\title{
A Review on Separation Techniques of Graphene Oxide (GO)/ Base on Hybrid Polymer Membranes for Eradication of Dyes and Oil Compounds: Recent Progress in Graphene Oxide (GO)/ Base on Polymer Membranes-Related Nanotechnologies
}

\author{
Elahe Dadvar ${ }^{1,2}$ and Alireza Heidari ${ }^{3 *}$ \\ ${ }^{1}$ Department of Environmental Engineering, Faculty of the Environment and Energy, Science and \\ Research Branch, Islamic Azad University, Tehran, Iran \\ ${ }^{2}$ Department of Environmental Engineering, West Tehran Branch, Islamic Azad University, Tehran, Iran \\ ${ }^{3}$ Faculty of Chemistry, California South University, 14731 Comet St. Irvine, CA 92604, USA
}

*Corresponding author: Alireza Heidari, Faculty of Chemistry, California South University, 14731 Comet St. Irvine, CA 92604, USA, E-mail:Scholar.Researcher.Scientist@gmail.com; Alireza.Heidari@calsu.us

\begin{abstract}
Nowadays, obtaining drink water for saving health of humans is very important. There have been various investigations about the cost effective and environmental friendly methods of water treatment. The purpose of the current study is reviewing the application of hybrid polymeric membranes Graphene Oxide (GO) as new techniques for separation of pollutants (Figures 1 and Figure 2) [1,2]. One of the methods for separation of containment is filtration. The filtration of pollutant is a useful method because of its limited need to energy and no production of chemical material, so less pollution. The hybrid polymeric membranes have many advantages such as permeation high flux, low antifouling and reducing odor compared to traditional kind. In addition, it can be used for separation of aromatic hydrocarbons which have four or more rings in waste water. Aromatic hydrocarbons are included in the priority list of pollutants of US EPA and European Union, especially those with four or more rings.
\end{abstract}

\section{Keywords}

Recent patents, Graphene oxide (GO), Hybrid polymer membranes, Separation techniques, Eradication, Dyes and oil compounds, Nanotechnologies

\section{Abbreviations}

GO: Graphene Oxide; SSA: Specific Surface Area; $\mathrm{TiO}_{2}$ : Titanium Dioxide; MF: Microfiltration; UF: Ultrafiltration; NF: Nanofiltration; RO: Reverse Osmosis; CA: Cellulose Acetate; PC:
Polycarbonate; PSF: Polysulfone Fluoride; PES: Poly Ether Sulfone; PVDF: Polyvinylidene Fluoride; MMM: Mixed Matrix Membrane; MB: Methylene Blue; MV: Methyl Violet; MO: Methyl Orange; CS: Chitosan; HM: Hybrid Membrane; AOPs: Advanced Oxidation Processes; rGO: Reduced Graphene Oxide; MWCNTs: Multi-Walled Carbon Nanotubes; TMP: Transmembrane Pressure; TDS: Total Dissolved Solid; RF: Rejection Flux

\section{Introduction}

By developing heavy industries during recent decades, availability of healthy drinking water becomes a global concern [3]. Pollutants such as gas petrochemical, pharmaceutical and organic substances, industrial dyes, microorganisms and heavy metals (including Cobalt, Cadmium, Mercury, Chromium and Lead) are typically observed in the water [4-9]. Because of high retention, these compounds possess harm effect like carcinogenetic in animal, humans' bodies and environment [10]. It is difficult to treat water by conventional physical methods such as flotation, aeration, coagulation and gravity settling. These methods have drawbacks such as high cost, using toxic compounds, large space, high energy consumption and producing secondly compounds. In recent decades, applications of clean water were se-

Citation: Dadvar E, Heidari A (2018) A Review on Separation Techniques of Graphene Oxide (GO)/ Base on Hybrid Polymer Membranes for Eradication of Dyes and Oil Compounds: Recent Progress in Graphene Oxide (GO)/Base on Polymer Membranes-Related Nanotechnologies. Clin Med Rev Case Rep 5:228. doi.org/10.23937/2378-3656/1410228

Accepted: August 08, 2018: Published: August 10, 2018

Copyright: (C) 2018 Dadvar E, et al. This is an open-access article distributed under the terms of the Creative Commons Attribution License, which permits unrestricted use, distribution, and reproduction in any medium, provided the original author and source are credited. 


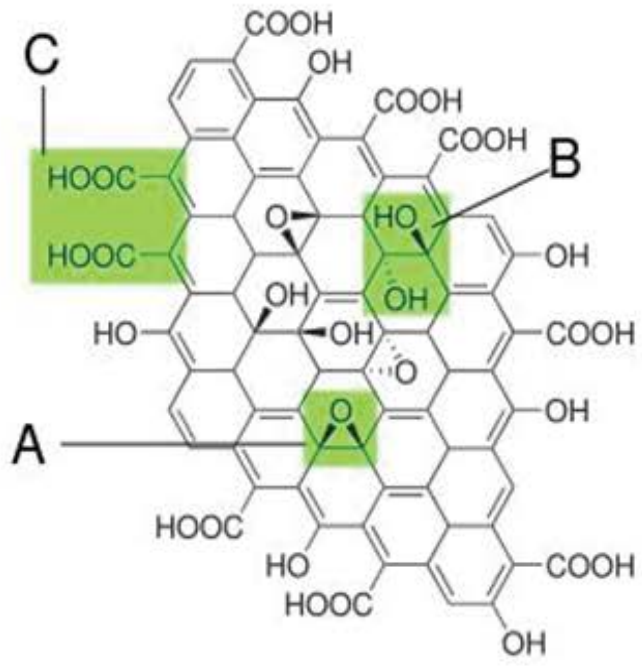

Figure 1: Structure proposed in 1998 with functional groups. A): Epoxy bridges; B): Hydroxyl groups; C): Pairwise carboxyl groups [1].

A

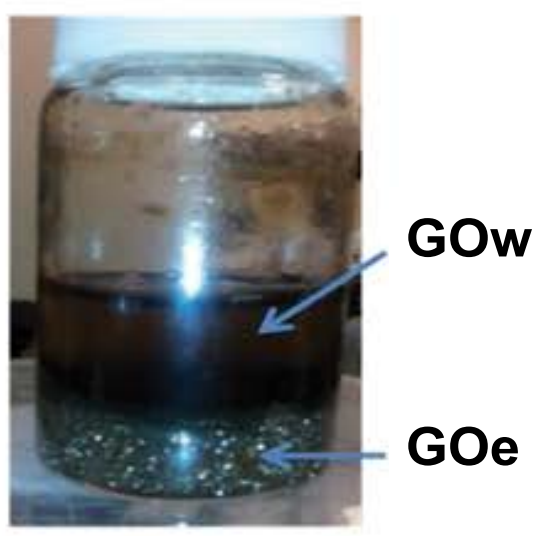

C

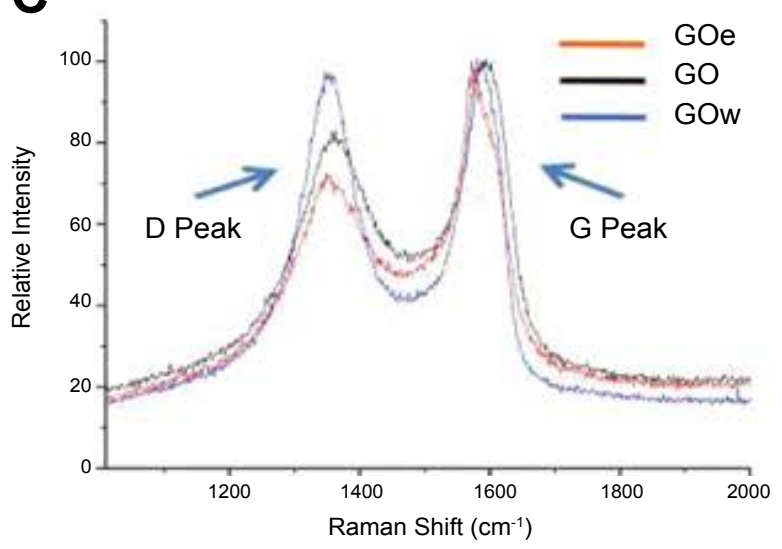

B
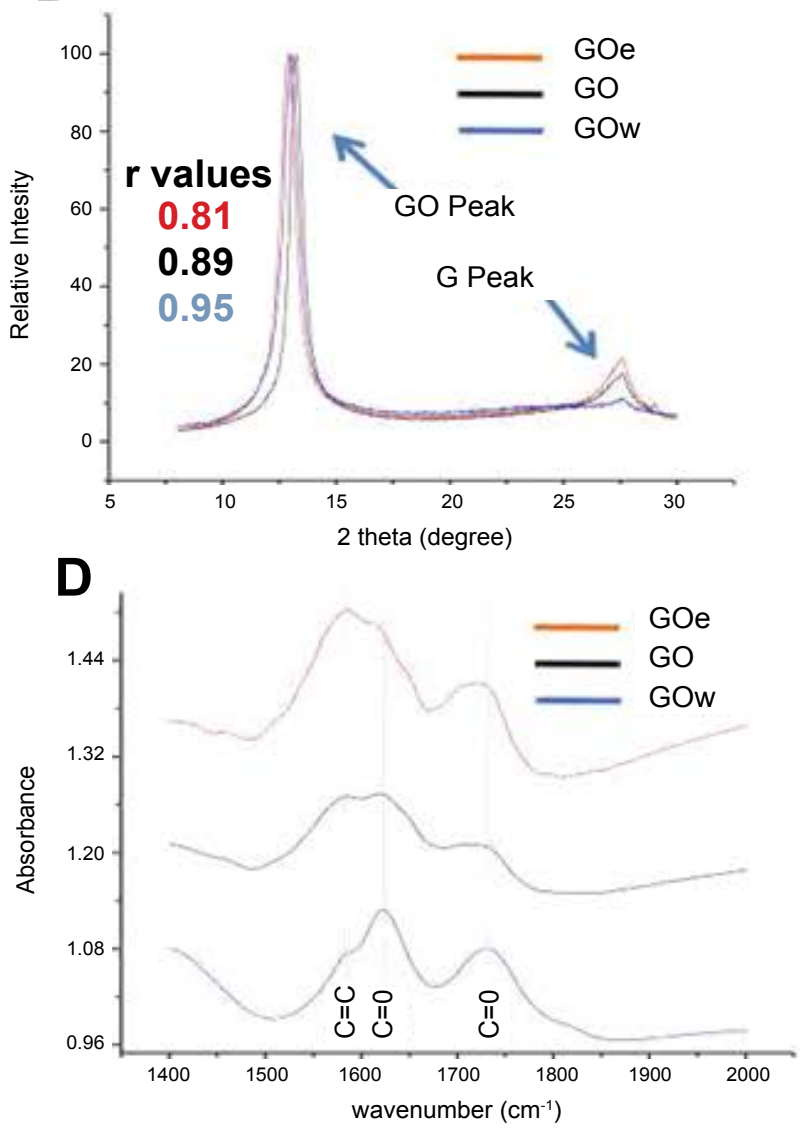

Figure 2: A) Image of fractionated GO. The upper phase contains GO suspended in water (GOw) and the lower region contains GO at the interface of a chloroform-in-water emulsion (GOe); B) Overlaid XRD spectra of the original GO sample (black), the GOw from the water phase (blue), and GOe from the emulsion phase (red); C) Overlaid Raman spectra of GO (black), GOw (blue), and GOe (red) showing the G and D peaks; D) Overlaid FTIR spectra of GO (black), GOw (blue), and GOe (red) highlighting changes in relative intensities of peaks at $1580 \mathrm{~cm}^{-1}\left(\mathrm{sp}^{2}\right.$-hybridized $\left.\mathrm{C}=\mathrm{C}\right), 1620 \mathrm{~cm}^{-1}$ (ketone $\mathrm{C}=\mathrm{O}$ ), and $1730 \mathrm{~cm}^{-1}(\mathrm{carboxyl} \mathrm{C}=\mathrm{O})$ [2].

verely increased [11-13]. With high efficiency and low energy consumption, filtration is one of the most appropriate technologies for decreasing pollution [14-18]. The formation of a good membrane is an important and practical step toward increasing the efficiency of water treatment; this film can be made from materials such as polymer, fiber, ceramic and Carbon nanotubes [19-22].

\section{Background}

Graphene is a single layer or few layers of graphite, 
Table 1: Band gap energy for some common semiconductor materials [46].

\begin{tabular}{|l|l|l|l|}
\hline Semiconductors & $\begin{array}{l}\text { Band Gap } \\
\text { Energy } \\
(\mathbf{e V})\end{array}$ & Semiconductors & $\begin{array}{l}\text { Band Gap } \\
\text { Energy } \\
(\mathbf{e V})\end{array}$ \\
\hline Diamond & 5.4 & $\mathrm{WO}_{3}$ & 2.76 \\
\hline $\mathrm{SdC}$ & 2.42 & $\mathrm{Si}$ & 1.17 \\
\hline $\mathrm{ZnS}$ & 3.6 & $\mathrm{Ge}$ & 0.744 \\
\hline $\mathrm{ZnO}$ & 3.436 & $\mathrm{Fe}_{2} \mathrm{O}_{3}$ & 2.3 \\
\hline $\mathrm{TiO}_{2}$ & 3.03 & $\mathrm{PbS}$ & 0.286 \\
\hline $\mathrm{CdS}^{\mathrm{NnS}}$ & 2.582 & $\mathrm{PbSe}_{2}$ & 0.165 \\
\hline $\mathrm{CdSe}$ & 3.54 & $\mathrm{ZrO}_{2}$ & 3.87 \\
\hline & 1.7 & $\mathrm{Cu}_{2} \mathrm{O}$ & 2.172 \\
\hline
\end{tabular}

a two-dimensional (2D) one atom thick nanomaterial consisting of $\mathrm{sp}^{2}$-hybridized Carbon packed in honey combed crystal lattice [23]. Scientists are heavily interested in Graphene due to its unique properties; including high Specific Surface Area (SSA) of $2600 \mathrm{~m}^{2} \mathrm{~g}^{-1}$ [24] or $2630 \mathrm{~m}^{2} \mathrm{~g}^{-1}$ [25], excellent thermal conductivity of 5000

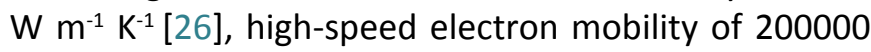
$\mathrm{cm}^{2} \mathrm{~V}^{-1} \mathrm{~s}^{-1}$ at $250{ }^{\circ} \mathrm{C}$ [27] and strong adsorption capacity on poly aromatic hydrocarbon [28].

Many efficient adsorbents [29] and photocatalysts [30] are developed for the removal and photocatalytic degradation of pollutants. Graphene mono layers have an excellent electrical conductivity $103 \mathrm{WmK}^{-1}$ [3]. Many sensitive biosensors, glucose biosensor [31] and fluorescent [32] were used as detector. Finally, chemical properties and chemical modification are also of particular interest for photocatalysis or separation of pollutant such as heavy metal and azo dyes. GO consists of Graphene sheets having functional groups $\mathrm{R}-\mathrm{O}-\mathrm{H}$ hydroxyl, epoxy, $\mathrm{COOH}$ and $\mathrm{C}=\mathrm{O}$. It causes Graphene has negative charge which can affect cationic compounds [33].

One of the interesting properties of $\mathrm{GO}$ is that it is a photocatalyser material in photoluminescence. $G O$ is a p-type semiconductor. The optical band gap of $G O$ is around $3.06 \mathrm{eV}$. Graphene is a suitable material as an alternative for photoanode due to its specific surface area and good capacity to transport electron.

Titanium dioxide $\left(\mathrm{TiO}_{2}\right)$ is the most important semiconductor among all of the semiconductors which are widely used with Graphene in many studies. Titanium dioxide is the oxide of Titanium, with a molecular weight of $79.87 \mathrm{~g} /$ mol and chemical formula of $\mathrm{TiO}_{2}$. One of the important properties of $\mathrm{TiO}_{2}$ is the photocatalytic activity. Also, the photocatalytic activity of $\mathrm{TiO}_{2}$ has been applied in a wide range of metal oxides and their sulfides [34,35] including $\mathrm{ZnO}$ [36], $\mathrm{WO}_{3}$ [37], $\mathrm{WS}_{2}$ [38], $\mathrm{Fe}_{2} \mathrm{O}_{3}$ [39], $\mathrm{V}_{2} \mathrm{O}_{5}$ [40], $\mathrm{CeO}_{2}$ [41], CdS [42] and ZnS [43]. ZnS is an II-VI semiconductor with a wide band gap ( $3.75 \mathrm{eV})$. ZnS is used in transistors, LEDs, photocatalysis and solar cells $[44,45]$. The band gap energy values for some common semiconductor materials are presented in Table 1 [46].

Graphene is one of the Carbon allotropes which possess photocatalic performance. One of the material photocatalytic performances of Graphene is related to the Carbon material. It has low toxicity, excellent electrical conductivity and thermal conductivity as well as other special properties such as electron-acceptor and electron-transport Dye Sensitized Solar Cell (DSSC), quantum-dot sensitized solar cell eradication of organic, ionic and biological pollutant water splitting [47-50].

\section{Preparation of GO}

GO was prepared from natural graphite powder according to the Hummers method [48] and many procedures have been described with some modification, previously [51,52]. Briefly, $3 \mathrm{~g}$ of graphite was added into $70 \mathrm{~mL}$ of sulfuric acid (98\%) and the resulted mixture was stringed at room temperature for $24 \mathrm{~h}$. Then, $300 \mathrm{mg}$ of Nitrate Sodium was added into the mixture and stirred for $1 \mathrm{~h}$. The dispersion was cooled by ice bath. Next, $15 \mathrm{~g}$ of $\mathrm{KMnO}_{4}$ was slowly added to the mixture during $15 \mathrm{~min}$. Afterwards, the temperature of mixture was kept to $40-50{ }^{\circ} \mathrm{C}$ while stirring for another $1 \mathrm{~h}$. The reaction was followed by adding $138 \mathrm{~mL}$ of DI water into the dispersion during $30 \mathrm{~min}$. Finally, $30 \mathrm{~mL}$ of $\mathrm{H}_{2} \mathrm{O}_{2}$ was added into the dispersion. The $\mathrm{pH}$ of solution was remained at 7. Next, the synthesized GO was dried at $60^{\circ} \mathrm{C}$ for $24 \mathrm{~h}$.

\section{Preparation of modified GO}

Modifications in the conditions of the Hummer's method can be improved to be efficient in Graphenebased $\mathrm{p}$-semiconductors production (it does not use Na${ }_{3} \mathrm{NO}_{3}$, increasing added amount of $\mathrm{KMnO}_{4}$ and volume ratio of $\mathrm{H}_{2} \mathrm{SO}_{4}: \mathrm{H}_{3} \mathrm{PO}_{4}$ in a 9:1 mixture), various advantages can be achieved such as fewer defects, higher efficiency, equivalent conductivity and no production of toxic gases. The mixture was stirred at $50^{\circ} \mathrm{C}$ for $12 \mathrm{~h}$. Then, the mixture was cooled at $25^{\circ} \mathrm{C}$, under vigorous stirring in an ice bath with adding $3 \mathrm{~mL} \mathrm{H}_{2} \mathrm{O}_{2}$. Therefore, the mixture was washed with DI water several times. This is considered as the most excellent method to prepare $\mathrm{GO}$ in large quantities [53].

\section{Characterization of GO by FT-IR and raman spec- troscopy}

Figure 3 depicts the FT-IR spectrum of GO. Fourier Transform Infrared (FT-IR) spectroscopy was used to detect chemical composition assignment $\left(\mathrm{cm}^{-1}\right): \mathrm{C}=\mathrm{O}$ (carbonyl/carboxy) groups at 1736.56; C $=\mathrm{C}$ (aromatics) at 1633.56; C-O (carboxy) at 1419.16; (epoxy) C-O group at 1267.74; C-O (alkoxy) at 1037.07 [54,55].

Furthermore, Figure 4 illustrates the Raman spectum of $G O$ includes $D$ and $G$ peaks where the $D$ peak at $\sim 1350\left(\mathrm{~cm}^{-1}\right)$ is the result of defects in the Graphene sheets and the $G$ peak at $\sim 1600\left(\mathrm{~cm}^{-1}\right)$ is the result of bond stretching of $\mathrm{sp}^{2}$ hybridized Carbons, respectively $[56,57]$. 


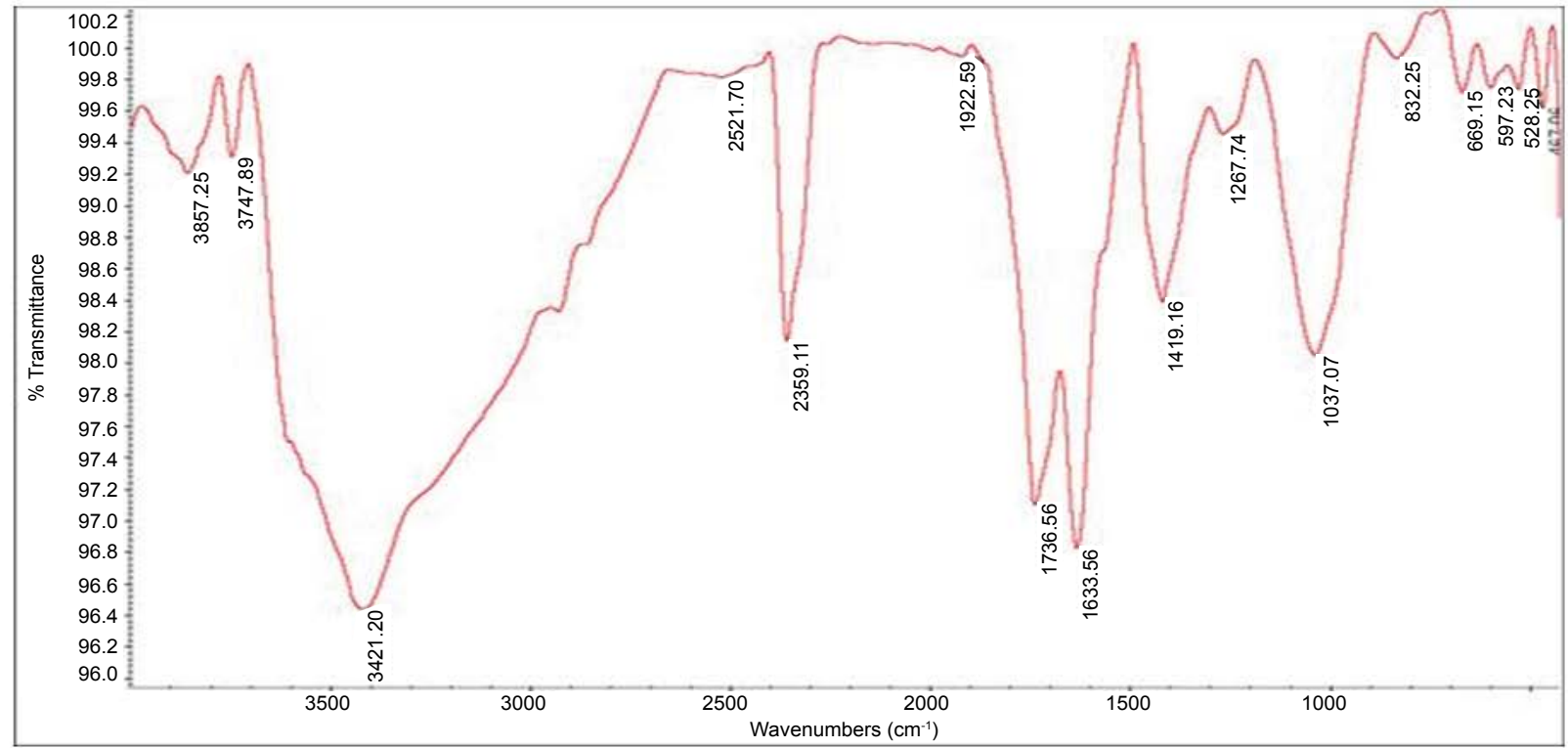

Figure 3: FT-IR spectrum of GO.

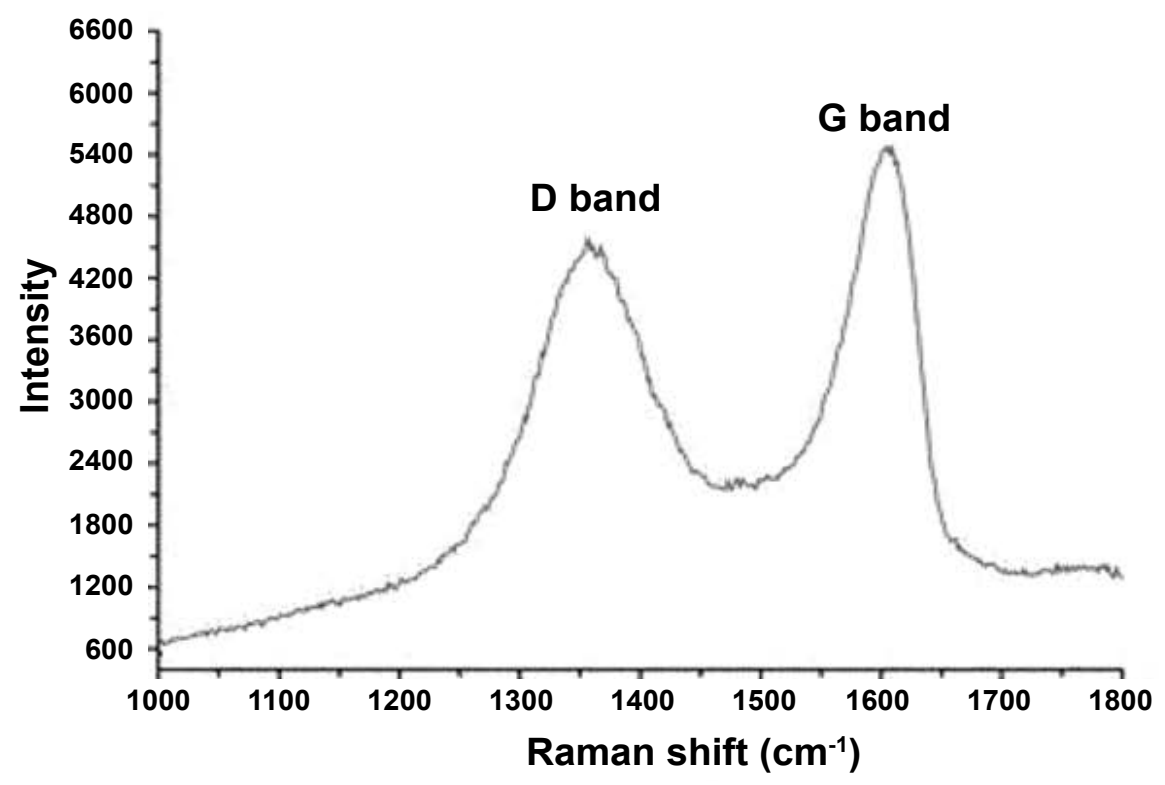

Figure 4: Raman spectrum of GO.

\section{Separation Techniques}

\section{Filtration}

As shown in Figure 5, membrane separation is based on three principles: Adsorption, sieving and electrostatics [58]. The type of membrane has relation with its pore size: Microfiltration (MF), Ultrafiltration (UF), Nanofiltration (NF) and Reverse Osmosis (RO) as shown in Table 2. Among the membrane processes, the advantage of Ultrafiltration (UF) with polymeric membrane is that it is able to omit pollutants such as organic pollutants, heavy metal, suspended solid and various dyes.

It should be noted that when the pore size of membrane is more than pollutant molecules' size, deep filtration occurs. In this regard, when the pore size of membrane is smaller than pollutant molecules' size, sieving or adsorption or surface filtration occurs. Furthermore, electrostatic reaction takes place for the reason of membrane and particles' charges. In this regard, when pollution membrane and particle have same charge, adsorption does not occur. But when pollution membrane and particle have opposite charge, adsorption occurs.

\section{Advanced technology in membrane}

In recent decades, ceramic and polymeric membranes have been increasingly used due to their strong mechanical characteristics, chemical stability, high efficiency for removing pollutants, high photocatalytic power and odor decline. They are produced in various types such as hollow fiber spiral and tubular structure.

Polymeric membrane: Different polymeric membranes such as Anionic Perfluorinated Polymer (Nafion), Cellulose Acetate (CA), Polycarbonate (PC), Polysulfone Fluoride (PSF), Poly Ether Sulfone (PES) and Polyvi- 


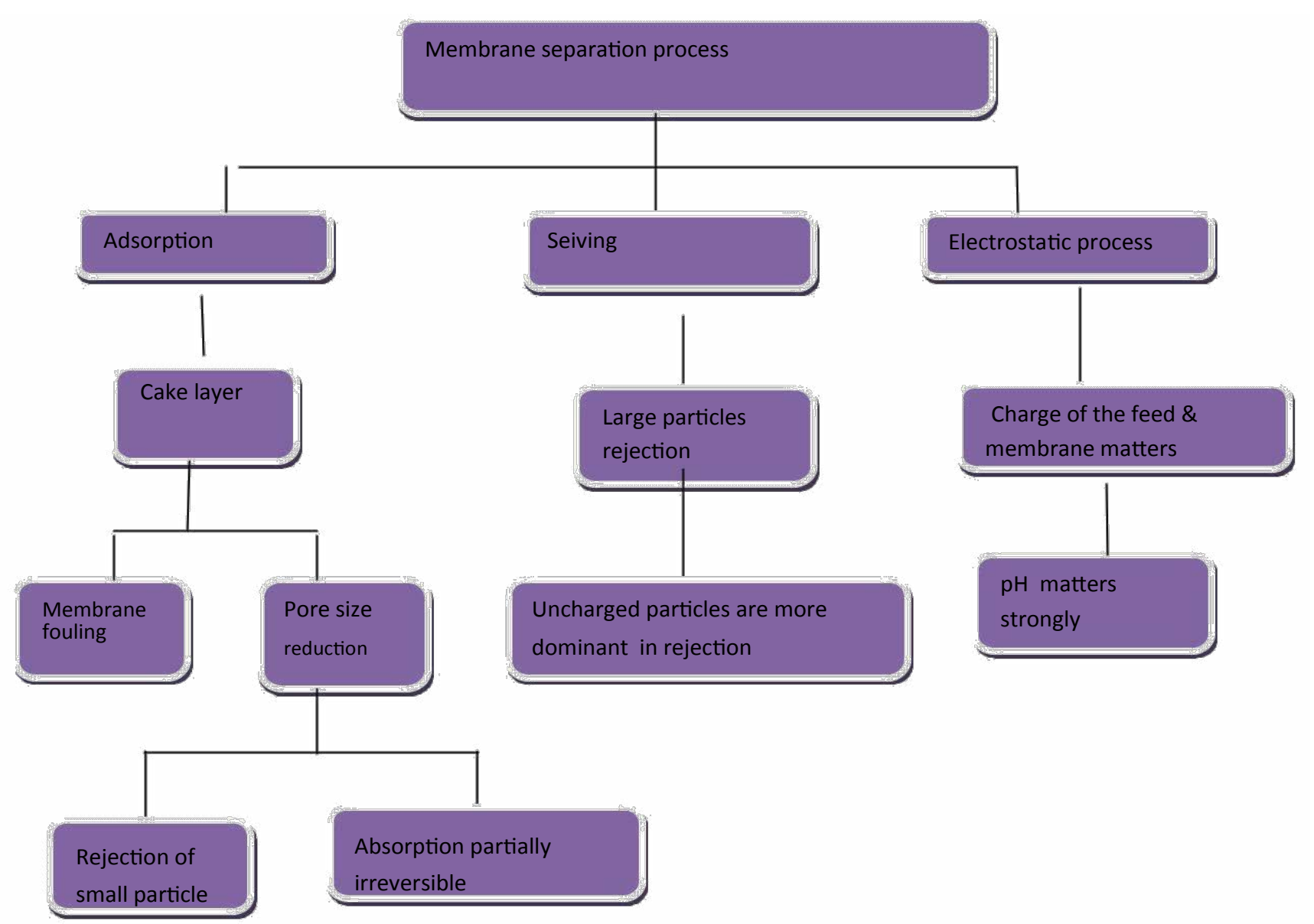

Figure 5: Schematic representing the basic principles involved in membrane separation [58].

Table 2: Membrane separation process [58].

\begin{tabular}{|c|c|c|c|}
\hline Pore Type & Membrane Type & Species & Dimension (nm) \\
\hline Macropores & Microfiltration & Yeasts \& fungi & $1000-10000$ \\
\hline \multirow[t]{2}{*}{$>50$} & $50-500$ & Bacteria & $300-10000$ \\
\hline & & Oil emulsion & $100-10000$ \\
\hline Mesopores & Ultrafiltration & Colloidal Solid & $100-1000$ \\
\hline \multirow[t]{4}{*}{$2-50$} & $2-50$ & Viruses & $30-300$ \\
\hline & & Protein/Polysaccharide & $30-300$ \\
\hline & & Humic/Nucleic Acids & 3-10 \\
\hline & & & $<3$ \\
\hline Micropores & Nanofiltration $\leq 2$ & Common antibiotics & $0.6-1.2$ \\
\hline \multirow[t]{3}{*}{$0.2-2$} & Reverse Osmosis & Organic antibiotics & $0.3-0.8$ \\
\hline & $0.3-0.6$ & Organic ions & $0.2-0.4$ \\
\hline & & Water & 0.2 \\
\hline
\end{tabular}

nylidene Fluoride (PVDF) were used in separation method. The polymer membranes have specific characteristics such as thermal stability, low energy requirements, chemical resistant, high flux and low fouling compared to usual kinds [59]. Although polymers are hydrophobic, many methods have been developed to enhance the properties of polymer membrane in the past decades. Among the methods, the strategy of doping inorganic oxide particles for casting the solution to prepare organic-inorganic composite membranes or Mixed Matrix Membrane (MMM) is promising, owing to its simple operating process. The main reason for the reduction of membrane fouling and increasing water permeability is increasing of membranes hydrophilicity which causes to decline the interpolation of oil and dyes compounds [59]. The asymmetric polymeric membrane is ideal for obtaining high permeability, good hydrophilicity and excellent chemical resistance to the feed solution.

\section{Separation of azo dyes}

The discharge of wastewater from textile industries into the environment is regarded as a main source of 
pollution and cause of eutrophication in rivers and lakes. There have been many studies for aiming to find a better way for separating azo dyes from wastewater. Fei Liu and his group reported a three-dimensional (3D) GO sponge from a GO suspension through a simple centrifugal vacuum evaporation method. They removed both Methylene Blue (MB) and Methyl Violet (MV) by GO sponge with good efficiency. The adsorption process completed with high efficiency of $99.1 \%$ for Methylene Blue (MB) and $98.8 \%$ for Methyl Violet (MV) in $2 \mathrm{~min}$. The effective parameters investigated on adsorption three-dimensional (3D) GO were temperature, $\mathrm{pH}$ and stirring speed. The adsorption mechanism follows the second-order kinetic equation [60].

Lulu Fan, et al. also reported synthesized GO/Magnetic Chitosan (CS) for absorption of Methylene Blue $(\mathrm{MB})$ in aqueous solution. The amount of adsorbent can be reduced using specific surface area of Chitosan (CS). The kinetic study fitted the pseudo second-order model. Although the equilibrium data well-modeled according to the Langmuir and Freundlich isotherm models, the best fitted results was observed in Langmuir model [61].

Tonghao Liua, et al. investigated adsorption capacity of Graphene at Methylene Blue (MB). The kinetic study illustrated that the adsorption of Methylene Blue (MB) onto Graphene fit the pseudo second-order model. The effective parameters investigated on adsorption $\mathrm{GO}$ were temperature, $\mathrm{pH}$, contact time and dosage in adsorption [62].

Lulu Fan and his group synthesized the magnetic $\beta$-cyclodextrin-chitosan/GO as a nanoadsorbent. $\beta$-cyclodextrin-chitosan/GO has good adsorption properties for the reason of magnetic properties of $\mathrm{Fe}_{3} \mathrm{O}_{4}$ as a functional group in Chitosan (CS) and also hydrophobicity of cyclodextrin. This magnetic nanoadsorbent has low cost and easy operation and can be extracted from aqueous solution. It will be used as other novel biosorbent suggested in future [63].

Hem Raj Pant and coworkers reported the synthesizing of $\mathrm{ZnO}$ micro flower nanoparticles. It assembled on $\mathrm{GO}$ which have excellent characteristic for removing the pollutants, especially the Methylene Blue (MB). ZnO nanoparticles can be recovered and extracted from reaction system which is useful for environment [64].

Jiaqian Qin, et al. also reported the synthesizing of ZnO microspheres-r GO nanocomposite. It had been used for photocatalytic degradation of Methylene Blue (MB) under UV irradiation. The better adsorption is in higher Brunauer-Emmett-Teller ( $\mathrm{N}_{2}$-BET) Spacific Surface Area (SSA) $\left(16 \mathrm{~m}^{2} / \mathrm{g}\right.$ for $\mathrm{ZnO}, 20 \mathrm{~m}^{2} / \mathrm{g}$ for ZRGO80 and $26 \mathrm{~m}^{2} / \mathrm{g}$ for ZRGO120). The best photocatalytic activity among of synthesized pure $\mathrm{ZnO}, \mathrm{P} 25 \mathrm{TiO}_{2}$ in this study was ZnO-rGO (4.06 wt. \% rGO) composite [65].

It is essential to determine the factors affecting the reaction rate and the mechanisms that control the adsorption, including adsorption at the surface, chemical reaction and diffusion mechanisms through kinetic evaluation. Pseudo-first-order and pseudo-second-order kinetic models are widely used to characterize adsorption. A pseudo-first-order kinetic model indicates that diffusion takes place from inside a layer and is based on solid capacity. A pseudo-second-order kinetic model indicates that chemical adsorption reduces the rate and controls the adsorption, which is based on solid phase adsorption.

The Langmuir, Freundlich and Tamkin models were used to determine the mechanism, superficial characteristics and adsorption tendency of experimental data at equilibrium. In the Langmuir model, adsorption takes place at a series of sites inside the adsorbent on the homogenous surface, every adsorption site have same adsorption power. The equation form is according to the following:

$$
\frac{C_{e}}{q_{e}}=\frac{1}{K_{L} Q_{0}}+\frac{C_{e}}{Q_{0}}
$$

where $\mathrm{q}_{\mathrm{e}}$ denotes the amount of pollutant adsorption onto the adsorbate $\mathrm{mg} / \mathrm{g}$, Ce denotes the final equilibrium concentration of the solution $(\mathrm{mg} / \mathrm{l}), \mathrm{KL}$ denotes the equilibrium constant Langmuir and $\mathrm{Q}_{0}$ denotes the maximum adsorption capacity at monolayer coverage $(\mathrm{mg} / \mathrm{l})$.

In the Freundlich (1906) isotherm, adsorption occurs in response to the heterogeneous surface having a nonuniform distribution of adsorption heat. The Freundlich model is an empirical model. The equation form is according to the below:

$$
\log q_{e}=\log K_{F}+\frac{1}{n} \log C_{e}
$$

where $\mathrm{K}_{\mathrm{F}}$ is the adsorption capacity at unit concentration and $1 / n$ is the intensity of adsorption and indicates the type of isotherm;

$1 / \mathrm{n}=0$ is irreversible, $0<1 / \mathrm{n}<1$ is desirable and $1 / \mathrm{n}$ $>0$ is undesirable. The Tamkin isotherm assumes that the adsorption heat of all molecules in a layer declines linearly due to the interaction between the adsorbent and the adsorbate. This model describes the interaction between the adsorbent and adsorbate.

All of previous experiments have been reported that the adsorption of Methylene Blue (MB) on the surface of Graphene were endothermic and spontaneous. The adsorption increases as the contact time increases. It is clear that the percentage removal of dyes increases by increasing the dosage of Graphene. All of above results show that $\mathrm{GO}$ plays important roles for $\pi-\pi$ interaction between aromatic rings like cationic dyes and $\mathrm{GO}$ or negative.

It should be noted that $\mathrm{GO}$ are used as heavy metals removal in nanocomposites, nanoadsorbates, etc. For example, Fang Fang and coworkers have functionalized $\mathrm{GO}$ as a heavy metals removal using aromatic diazoni- 
um salts. A new designed GO-NH $\mathrm{NH}_{2}$ has excellent adsorption for removal of Co (II) ions. $\mathrm{Ca}^{+2}$ and $\mathrm{Mg}^{+2}$ are the usual ions with $\mathrm{Co}$ (II) in nature; they are increased the adsorption of Cobalt [66].

Chaohui Ruan and his groups also investigated on novel porphyrin sensitized $\mathrm{TiO}_{2} /$ Graphene. The effects of photocatalytic properties of $\mathrm{TiO}_{2} / \mathrm{Graphene}$ and porphyrin synthesis $\mathrm{TiO}_{2} /$ Graphene under visible light were studied. The results showed the improved photocatalytic degradation Methylene Blue (MB) under visible light with the novel composite [67].

According to the Chao Xu, et al. synthesis of GO-TiO composite as filtration membrane to remove of (Meth$\mathrm{yl}$ Orange (MO) and Rhodamine $\mathrm{B}$ ) from the water was successful. These attached $\mathrm{TiO}_{2}$ can shore up $\mathrm{GO}$ sheets and enlarge the interlayer distance, which leads to the formation of special pores and channels in the films, making them good treatment of water [68].

Peng Gaoa and coworkers synthesized $\mathrm{GO}^{-\mathrm{TiO}_{2}} \mathrm{mi}-$ crosphere as membrane filtration. They used a commercial Cellulose Acetate (CA) membrane as a kind of polymer $\mathrm{GO}_{-} \mathrm{TiO}_{2}$ nanohybrid was uniformly assembled on the surface of Cellulose Acetate (CA) membrane that has extraordinary removal pollutant of water [69].

Yong Gao, et al. found effective of $\mathrm{GO}^{-\mathrm{TiO}_{2}}$ assembled on polysulfone base membrane which show significantly improved photodegration of Methylene Blue (MB) under UV irradiation. The synthesizing method of Hybrid Membrane (HM) in their study was LbL (Layer-by-Layer). The LbL (Layer-by-Layer) method has the ability to form a Hybrid Membrane (HM) [70].

The LbL (Layer-by-Layer) method has the ability to form a Mixed Matrix Membrane (MMM). This experiment used a Gold covered sensor to determine the mass of $\mathrm{TiO}_{2}$ and $\mathrm{GO}$ during the LbL (Layer-by-Layer) procedure. The sensor was coated using a base polymer membrane. The sensor was put in a desiccator for drying. After that, it was put in DI water. A fixed concentration on the surface of the sensor was at $0 \mathrm{ng} /$ $\mathrm{cm}^{2}$ after $15 \mathrm{~min}$ and the DI water was changed with $\mathrm{TiO}_{2}$ solution. $\mathrm{TiO}_{2}$ nanoparticles were adsorbed on the base polymer after $2 \mathrm{hr}$, the mass of the nanoparticle slowed down and became stabilized. After that, $\mathrm{TiO}_{2}$ solution was replaced with DI water for the removal of nanoparticles. Next, the $\mathrm{TiO}_{2}$ coated sensor was soaked in the GO solution. In particular, the advantage of LbL (Layer-by-Layer) properties of the membrane can be readily controlled through polymer compositions, concentrations, numbers of applied layers and application conditions/methods [71].

Photocatalytic nanocomposite films of Titanium dioxide $\left(\mathrm{TiO}_{2}\right) /$ polyoxometalate $\left(\mathrm{Na}_{4} \mathrm{~W}_{10} \mathrm{O}_{32}\right.$, abb. $\left.\mathrm{W}_{10} \mathrm{O}_{32}\right)$ were prepared via electrostatic LbL (Layer-by-Layer) self-assembly method by Ping Niu and coworkers. The influence of operational parameters was studied includ- ing bilayer number of films, initial dye concentration and electron acceptor. The UV light catalytic activities were evaluated by the degradation of Methyl Orange (MO) aqueous solution as pollutant. The experimental results show that the degradation rate of Methyl Orange (MO) decreases with an increase of initial dye concentration. Degradation of Methyl Orange (MO) and the photodecolorization follows first-order kinetics according to the Langmiur- Hinshelwood kinetics [72].

Simona Filice and his groups also investigated effectiveness of permeation flux of pollutant water for anatase-type $\mathrm{TiO}_{2}$ nanoparticles, $\mathrm{GO}$ and organo-modified $\mathrm{GO}$ (abbreviated as $\mathrm{GO}_{\text {sutF }}$ ). All membranes were prepared by the solvent casting method. The results showed excellent removal of Methyl Orange (MO) by $\mathrm{GO}_{\text {sULF }}$ during less than three hours UV irradiation [73].

Prototype composite membranes was produced and prepared through partial reduced of $\mathrm{GO}^{-\mathrm{TiO}_{2}}$ as photocatalytic ultrafiltration water treatment under visible light for treating azo dyes such as Methyl Orange (MO) and Methylene Blue (MB) by Chrysoula $P$, et al. Among all the membranes, GO-TiO ${ }_{2}(\mathrm{GOT}-10)$ was the best membrane for removing Methyl Orange (MO) under UV irradiation and $\mathrm{GO}-\mathrm{TiO}_{2}$ was the best membrane for removing Methylene Blue (MB). GOT-10 has the higher photocatalytic activity compared to GOT-5. The amounts of Methylene Blue (MB) and Methyl Orange (MO) which were removed by $\mathrm{GO}-\mathrm{TiO}_{2}$ (GOT-10) under UV irradiation are $7.9,4.9 \mathrm{mg} / \mathrm{min}$, respectively [74].

Song Bai and coworker synthesized RGO-MFe $\mathrm{O}_{4}$ hybrids with slovothermal method. The results of experiment showed the hybrid removed over $92 \%$ Rhodamine $\mathrm{B}(\mathrm{RhB})$ and $100 \%$ Methylene Blue (MB) with a concentration of $5 \mathrm{mg} / \mathrm{L}$ within $2 \mathrm{~min}$. The kinetic data were using pseudo-second-order kinetics. The hybrids RGO$\mathrm{MFe}_{2} \mathrm{O}_{4}$ was separated by magnate which was one of advantages for adsorbent from pollutant water [75].

Synthesizing of Graphene/Magnetite composite by solvothermal method for removal of Methylene Blue (MB) from aqueous solution accomplished by Lunhong Aia and his worker. The kinetics and isotherm well described by pseudo-second-order kinetic and Langmuir isotherm model, respectively. Additionally, magnetics nanoparticles (NPs) also showed advantages such as low toxicity, low cost and eco-friendliness [76].

\section{Separation of oil compounds}

Polycyclic Aromatic Hydrocarbons (PAHs) can be found in all environmental compartments, atmosphere, soil, aqueous, etc. These compounds are usually generated by natural and anthropogenic processes and can be released into the environments through different ways. There are three types of antropogenic sources of Polycyclic Aromatic Hydrocarbons (PAHs): Phytogenic, petrogenic and pyrogenic sources. These sources are associated with the generation of high molecular weight 
Polycyclic Aromatic Hydrocarbons (PAHs) which include creosote, coal tar, which is released into the environment in the form of exhaust and solid residues. Phytogenic-hydrocarbon compounds were derived from plants [77-79]. These compounds are 16 and classified as hazardous compounds by World Health Organization (WHO).

Ainhoa Rubio-Clemente, et al. investigated the methods for removing Polycyclic Aromatic Hydrocarbons (PAHs) from aqueous environment by chemical treatments. Advanced Oxidation Processes $\left(\mathrm{AOP}_{\mathrm{s}}\right)$ coupled with biological treatments seems to be one of the best solutions for the treatment. In recent decades, Advanced Oxidation Processes $\left(\mathrm{AOP}_{\mathrm{s}}\right.$ ) have become useful. This process is based on the production of super active species such as hydroxyl $(\mathrm{OH})$, which is capable of oxidizing a wide range of materials, but its action is non-selective [80].

Mahdie Safarpour, et al. used reduced $\mathrm{GO}^{-\mathrm{TiO}_{2}}$ nanocomposite with variant molar ratios on the Polyvinylidene Fluoride (PVDF) ultrafiltration membranes for treatment. Series of Mixed Matrix Membrane (MMM) Polyvinylidene Fluoride (PVDF) ultrafiltration were prepared by assembled $\mathrm{GO}, \mathrm{TiO}_{2}$ and $\mathrm{rGO}-\mathrm{TiO}_{2}$ nanocomposite using the phase inversion way. The membranes modified with $0.05 \mathrm{wt}$. $\% \mathrm{rGO}^{-\mathrm{TiO}_{2}}$ nanocomposite with rGO to $\mathrm{TiO}_{2}$ ratio of $70 / 30$ had the greatest hydrophilicity. The bovine serum albumin used as pollutant in this study [81].

Based on Na Wang and his group achievement about GO synthesis according to the Hummers-Offeman method, this technique can be used in sorption of soluble diesel oil from water, too. The adsorption isotherm well fitted to the Freundlich isotherm. Soluble oil molecules were strongly adsorbed on the surface of Graphene by hydrophobic interactions, $\pi-\pi$ bonds and Van der Waals reaction. This sorption process composed physical and chemisorption. In comparison of equilibrium sorption capacity of soluble diesel oil on Graphene, expanded Graphite and activated Carbon, Graphene has highest equilibrium adsorption $241.88 \mathrm{mg} \mathrm{g}^{-1}$ [82].

X.S. Yi, et al. modified Polyvinylidene Fluoride (PVDF) by nano-sized $\mathrm{TiO}_{2} / \mathrm{Al}_{2} \mathrm{O}_{3}$ to separate oil/water emulsion by phase inversion method. The effective operating parameters such as initial concentration, Trans Membrane Pressure (TMP), Total Dissolved Solid (TDS) and $\mathrm{pH}$ were investigated. All the modified Polyvinylidene Fluoride (PVDF) membranes exhibited higher Rejection Flux (RF) and better antifouling property compared to the bare Polyvinylidene Fluoride (PVDF) membrane under the same operational conditions. The Rejection Flux (RF) decreased sharply by increase in oil concentration from 20 to $400 \mathrm{mg} / \mathrm{l}$. The influence of $\mathrm{pH}$ between 2-6.8 was not significant. However, after $\mathrm{pH} 10$, the Rejection Flux (RF) was decreased. Total dissolved solid has no significant influence on Rejection Flux (RF) until 8000 mg/l. There was good flux recovery when Mixed Matrix Membrane (MMM) washed by pure water and $\mathrm{NaClO}$ [83].
Yuqing Zhang and coworker studied on phosphorylated $\mathrm{TiO}_{2}-\mathrm{SiO}_{2}$ particles/polysulfone composite membrane for wastewater treatment. At the first step, Phosphorylated $\mathrm{TiO}_{2}-\mathrm{SiO}_{2}$ (PTS) particles were successfully prepared by sol-gel method and then, composite membrane was prepared by phase inversion. The results showed that composite membrane was a suitable membrane for treating oily waste water. Phosphorylated $\mathrm{TiO}_{2}-\mathrm{SiO}_{2} /$ Polysulfone (PTS/PSF) membrane has good permeation flux and antifouling compared with other prepared membranes. The operating pressure showed when pressure was increased, the membrane pores became blocked and also permeation flux reduced. The operating temperature and the influence of different oil concentration were investigated [84].

R. Jamshidi Gohari and his groups synthesized a novel Polyethersulfone (PES)/Hydrous Manganese Dioxide $\left(\mathrm{HMO}_{2}\right)$ as a new hybrid matrix membrane with improved anti-fouling properties for oily wastewater (TOG or Total Oil and Grease) treatment. PES/ $\mathrm{HMO}_{2}$ membrane showed excellent oil rejection and Flux Recovery Rate (FRR) when the concentration was 1000 ppm compared to the other membranes. Inorganic Hydrous Manganese Dioxide $\left(\mathrm{HMO}_{2}\right)$ nanoparticles was synthesized by permanganate in accordance to the Parida's method [85].

Vahid Vatanpour and coworkers synthesized novel antibifouling nanofiltration polyethersulfone membrane by embedding $\mathrm{TiO}_{2}$ coated Multi-Walled Carbon Nanotubes (MWCNTs). The flux for protein solution was measured at 5 bar for $2 \mathrm{~h}$. The pure water flux, contact angle and hydrophilicity of membrane increased by assembled $\mathrm{TiO}_{2}$ on the surface of Multi-Walled Carbon Nanotubes (MWCNTs). $0.1 \mathrm{Wt} \% \mathrm{TiO}_{2}$ coated on MultiWalled Carbon Nanotubes (MWCNTs) showed the highest antifouling properties due to lowest surface roughness [86].

Polysulfone is one of the polymers which are used for preparing Mixed Matrix Membrane (MMM), PSF functionalized by $\mathrm{SiO}_{2}$ nanoparticle, by A. L. Ahmad and coworkers. The pollutant candidate for separation is oil in water. The result showed that the addition of nanoparticles improved antifouling and permeation flux properties by increasing the pore size. The pore size of the $\mathrm{SiO}_{2}$ filled membrane increased and became interconnected due to the interfacial stresses between the polymer and filler $\mathrm{SiO}_{2}$ nanoparticles) [87].

$\mathrm{GO}^{-\mathrm{TiO}_{2}}$ nanocomposite was assembled on poly sulfone for treatment of humic acid by Mahendra Kumar, et al. The different loading amount of adding $\mathrm{GO}^{-} \mathrm{TiO}_{2}$ on PES were 0-5 Wt \% by the Non-solvent Induced Phase Separation (NIPS) method. Different concentration of Hyaluronic Acid (HA) prepared to test the antifouling and removal efficiency, increasing concentration of Hyaluronic Acid (HA) which decline efficiency removal of membrane containing $5 \mathrm{wt} \%$ nanocomposite (MG-5). 
The membrane MG-5 had ability to remove $98.7 \%$ of Hyaluronic Acid (HA) from its $10 \mathrm{ppm}$ solution at $\mathrm{pH}=$ 7. Irreversible fouling decreased by increasing $\mathrm{GO}_{-} \mathrm{TiO}_{2}$. The lowest irreversible fouling is for MG-5 which has highest nanoparticles [88].

Huiqing Wuet, et al. synthesized the Polysulfone (PSF)-based Hybrid Membranes (HMs) by doping with $\mathrm{SiO}_{2}$-GO nanohybrid. 0.3 Wt \% GO-SiO $2 / \mathrm{PSF}$ among other membrane showed the best antifouling, permeation flux rate protein rejection. The rejection to egg albumin as containment was at a high level (98\%). PSF, GO/PSF, $\mathrm{SiO}_{2} /$ PSF were membranes which tested by Huiqing $\mathrm{Wu}$ and coworkers [89].

M. Padaki and his workers also investigated about the membrane separation in oil-water. The results showed that membrane separation process is economically effective compared to other commercial methods. They reported several operating parameters influencing on the ceramic and polymeric membranes. The surface modification by particular monomers and nanohybrids enhanced the Mixed Matrix Membrane (MMM) performance and showed better antifouling and hydrophilicity properties [58].

Zonghua Wang, et al. synthesized novel GO-blended Polyvinylidene Fluoride (PVDF) ultrafiltration membranes. They blended various amount of GO $(0.1,0.15$, $0.2,0.25$ and 0.3 ) on the Polyvinylidene Fluoride (PVDF). The results showed that when the content of GO added in the casting solution was $0.20 \mathrm{wt} . \%$, the water flux and porosity were $457.86 \mathrm{I} / \mathrm{m}^{2} . \mathrm{h}, 70.7 \%$, respectively. The properties of this membrane were better than other ones. The GO blend Polyvinylidene Fluoride (PVDF) membrane displayed higher water flux recovery ratio compared to the pure Polyvinylidene Fluoride (PVDF) membrane [90].

According to the Zhong-Kun Li, et al. PVDF/SiO ${ }_{2} @$ GO Nanohybrid Membranes (NHMs) synthesized via thermally induced phase for separating the pollutants. Different amount of $\mathrm{GO}_{-} \mathrm{SiO}_{2}(0,0.3,0.6,0.9$ and 1.2) assembled on the Polyvinylidene Fluoride (PVDF). The M-4 presented the highest Bovine Serum Albumin (BSA) rejection and the lowest permeation flux as $91.7 \%$ and 182.6 Lm, respectively. However, more $\mathrm{SiO}_{2} @ G O$ addition (1.2 wt\%) led to the outstanding pure water permeation flux and much lower Bovine Serum Albumin (BSA) rejection. The melting temperature $(\mathrm{Tm})$ increased with the addition of nanohybrid up to 0.9 wt\%. More $\mathrm{SiO}_{2} @$ GO addition (1.2 wt\%) led to a small reduction [91].

According to the results of all experiments, optimum operating parameter shows that suitable operating temperature should be between $25-30{ }^{\circ} \mathrm{C}$. By increasing oil concentration, the membranes permeate flux declines. One of the reasons for flux declination is concentration polarization on the surface of membrane as the oil concentration increases. Also, when operating tem- perature increases, the membrane pore will be blocked, tend to decline of water permeate flux. According to the R. Jamshidi Gohari, the permeation flux under different $\mathrm{pHs}$ were not only affected membranes properties but influenced oil dropt size [85].

\section{Other Applications for Removal Pollutant}

Wenbo Lu, et al. reported synthesizing of $\mathrm{GO}_{-}-\mathrm{SiO}_{2}$ by combining sonication with sol-gel technique. After that, $\mathrm{GO}_{-} \mathrm{SiO}_{2}$ functionalized with AgNP. AgNP/F-SiO $/$ GO nanocomposites were prepared. The results showed that glucose biosensor can be used for the glucose detection in human blood serum [92].

Another application for $\mathrm{GO}$ is used for antibacterial and antifouling in mixed matrix membrane. Preparation and characterization of HPEI-GO/PES ultrafiltration membrane with antifouling and antibacterial properties was studied by Liang Yu and coworkers. The Ultrafiltration (UF) membrane showed effective antibacterial performance against Escherichia coli (E. coli) [93].

On the other hand, complications related to infectious diseases have significantly decreased due to the availability and use of a wide variety of antibiotics and antimicrobial, antibacterial and biological agents. However, excessive use of antibiotics and antimicrobial, antibacterial and biological agents over years has increased the number of drug resistant pathogens. Antibiotics and antimicrobial, antibacterial and biological multidrug resistance poses serious risks and consequently research attention has refocused on finding alternatives for antimicrobial treatment. Among the various approaches, the use of engineered nanostructures is currently the most promising strategy to overcome microbial drug resistance by improving the remedial efficiency due to their high surface-to-volume ratio and their intrinsic or chemically incorporated antibacterial activity. GO, a two-dimensional ultra-thin nanomaterial, possesses excellent biocompatibility, putting it in the forefront for different applications in biosensing, drug delivery, biomedical device development, diagnostics and therapeutics. GO-based nanostructures also hold great promise for combating microbial infections. Yet, several questions remain unanswered such as the mechanism of action with the microbial entities, the importance of size and chemical composition in the inhibition of bacterial proliferation and adhesion, cytotoxicity, and other issues when considering future clinical implementation [94-235].

\section{Results and Discussion}

As previously mentioned, GO can improve ultrafiltration membrane hydrophilicity, high permeation flux, mechanical properties and salt retention; it has been used in separation field.

\section{Summary of research findings and achievements}

Du Chunhui and coworkers prepared Chitosan mod- 
ified-Graphene Oxide (CS-GO) nano composite positive osmotic membrane. In many polymers, Chitosan (CS) is a biodegradable, non-toxic and bio-compatibility. The natural polysaccharide polymer is reusable, distributed in nature and it has a rich source. It is a very useful, environmentally friendly material widely used in medicine, food, chemical, membrane separation and other fields. As a natural polymer, membrane material has been widely used in the preparation of ultrafiltration, nanofiltration, reverse osmosis membranes and smart responsive film. The various amount of percentage by mass $\mathrm{GO}$ add to nanocomposite $0.1 \%-1.0 \%, 2 \%-5 \%$ of Chitosan (CS), $0.1-0.3 \%$ of a hydrophilic additive. The results of their patent on nanocomposite show that a better salt interception effect can be achieved via a unique sheet structure of GO [236].

He Linghao, et al. synthesized modified polyvinylidene difluoride (PVDF) super-hydrophobic material and preparation method. The result of study show that the modified polyvinylidene difluoride (PVDF) superhydrophobic material has excellent oil absorption performance and can be used for efficiently separating oil and water where the amount of the (G)/PVDF or (GO)/ PVDF is (1 to 5) $(100 ; 3)$ under a closed condition [237].

According to the Xu Nanping and his groups, who investigated the enhanced GO hollow fiber composite membrane and preparation method thereof. The prepared membrane was strong in hydrophilicity, and the water permeability of the composite membrane was greatly improved. The thickness of the membrane separation layer was $0.01-1 \mathrm{~mm}$ and the membrane pore diameter of the enhanced GO hollow fiber composite membrane is 1-500 (nm) [238]. LbL (Layer-by-Layer) assembly of GO membranes via electrostatic interaction and elucidation of water and solute transport mechanisms also reported by Baoxia Mi and coworkers. The purification of the water and removing contaminant was excellent [239].

Peng Wang, et al. also provided thin films of nanoscale materials. A solution for creating micro arrays on thin film material surfaces was provided. It was demonstrated that filtration-based membrane preparation had potential to impact the produced rGO membrane property. A vacuum filtrated GO or rGO membrane has two surfaces, which are formed at different interfaces [240].

Jae Min Hong and his workers described a method for preparing an asymmetric porous membrane by a dry- wet phase inversion method. The results showed higher permeability because of high hidropilicity and excellent rejection ability of the asymmetric membrane for the sake of high porosity and uniform pore size of mixed matrix membrane [241].

\section{Summary of recent patents}

Meng Chuan Koh, et al. also investigated the meth- ods for forming GO/polymer composite membranes. Their patent is recorded. The ratio of mass GO embedded to 14 wt\% PSF was $0.0,0.5$ and 1.0 wt\%. The method for preparation was wet phase inversion [242].

Ho Bum Park and coworkers also prepared composite separation membrane including GO coating layer and method for manufacturing. The composite separation membrane of the invention has high selectivity for Carbon dioxide. The concentration of the GO in the dispersion obtained preferably from 0.5 to $1.5 \mathrm{~g} / \mathrm{L}$ [243].

Nanocomposite ultrafiltration membrane containing $\mathrm{GO}$ or reduced Graphene Oxide ( $\mathrm{rGO}$ ) and preparation method thereof also reported by Saira Bano, et al. The polyacrylonitrile (PAN)/GO nanocomposite ultrafiltration membrane has improved mechanical properties; high permeability and high salt rejection ratio and excellent anti-fouling property. Wherein the GO or rGO was present in an amount of 0.1-10 wt \% based on the total weight of the nanocomposite ultrafiltration membrane. Meanwhile, an ultrafiltration membrane including only a hydrophobic polymer is susceptible to fouling. Therefore, according to the their exposure, a hydrophobic polymer matrix is impregnated with $\mathrm{GO}$ or $\mathrm{rGO}$ to enhance hydrophilic property so increasing permeation and to control the roughness of the membrane surface so that the anti-fouling property may be improved [244].

The patent of Feng Kai, et al. reported added go on the polymer Hybrid Membrane (HM) for exchanging proton. The prepared GO was added to the polymer solution. Proton exchange especially at high temperatures and/under low humidity environment has improved. The exchange of proton on the Hybrid Membrane (GO$\mathrm{HM}$ ) is better than pure polymeric membrane [245].

Reported no patent of GO prepared by blending method to the Nafion (perfluorosulfonic acid resin) matrix was prepared by Bong Gill Choi and coworkers. The Hybrid Membrane (HM) was proton exchange film and application in fuel cell [246].

The asymmetric composite membrane synthesized by Nouran Ashraf and coworkers. It was containing a polymeric matrix and Carbon nanotubes within a single membrane layer, wherein the Carbon nanotubes were randomly oriented within the polymeric matrix and the composite membrane was formed by phase inversion. The invention also relates to a desalination method using the composite membrane [247].

With increasing of various containment in the water, it is critical to find a way for obtaining drinking water with low consumption energy and no production of chemical material. This invention reported by Rahul Nair, et al. Pervaporation (or pervaporative separation) is a method of separating mixtures of liquids by partial vaporization through a non-porous or porous membrane [248]. 
Zhengtang Luo and coworkers prepared methods for synthesizing GO with high surface area, electrical conductivity for using in sensor and device [249].

The forward osmosis composite membrane was a polysulfone-sulfonated polysulfone-inorganic filler blend/polyamide composite membrane synthesized by $\mathrm{Xu}$ Tongwen and his groups. Since conventional permeable membrane is generally used in the Reverse Osmosis (RO) system the permeate traditional forward osmosis is low than theoretical value, a high-water flux forward osmosis composite membrane and the preparation method was invented by their group. The method used for synthesis was phase inversion [250].

Graphene membrane filtration and its production method for removing alcohol and water, with efficiency close to $100 \%$, synthesized by Hong Wei-song, et al. [251].

The polyelectrolyte membrane is disposed between the positive and the negative electrode and can include a sulfonated tetrafluoroethylene (PTFE) based fluoropolymer-copolymer that can be subjected to ultraviolet/ ozone $\left(\mathrm{UV} / \mathrm{O}_{3}\right)$ exposure. The metallized nanoparticles increase the efficiency of the fuel cell by at least $50 \%$ when the feed gas includes at least 1000 ppm Carbon patented by Miriam Rafailovich, et al. [56,57,94-235, 252-256].

\section{Conclusions, Perspectives, Useful Suggestions and Future Studies}

We have summarized special characteristics of GO and several investigations about adsorption or filtration of oil compounds by polymeric compounds. The results show high permeation flux, reduce antifouling in polymeric compounds compare to traditional kinds at several investigations. Fouling of membrane occurs due to formation of cake layer on the membrane surface or adsorption on to the membrane surface or within the pores. Although many investigations about the fouling of the membrane carried out by scientists, it will be used for reducing the fouling and increasing the flux. Polycyclic Aromatic Hydrocarbons (PAHs) are neutral, non-polar molecules found in charcoal and in $\operatorname{tar}$ deposits. These are also produced by the incomplete combustion of organic materials (e.g., in engines and incinerators, when biomass burns in forest fires, etc.). Exposure to Polycyclic Aromatic Hydrocarbons (PAHs) has also been linked with carcinogenetic disease and poor germinal development. Because of specific characteristics of polymeric membrane such as thermal stability, low energy requirements, chemical resistant, high flux and low fouling compared to usual kinds, it will be used to remove Polycyclic Aromatic Hydrocarbons (PAHs) from wastewater at future by different polymeric membranes such as Polyvinylidene Fluoride (PVDF), cellulose acetate poly ether sulfone and polycarbonate.

\section{References}

1. Heyong He, Jacek KI, Michael FO, Anton LE (1998) A new structural model for graphite oxide. Chemical Physics Letters 287: 53-56.

2. Harish V Kumar, Steven J Woltornist, Douglas H Adamson (2016) Fractionation and characterization of graphene oxide by oxidation extent through emulsion stabilization. Carbon 98: 491-495.

3. Menacham El, William PH (2011) The future of seawater desalination: Energy technology and the environment. Science 333: 712-717.

4. Shannon MA, Bohn PW, Elimelech M, Georgiadis JG, Mariñas BJ, et al. (2008) Science and technology for water purification in the coming decades. Nature 452: 301-310.

5. Satinderpal K, Gopal R, Wun Jern N, Seeram R (2008) Next generation fibrous media for water treatment. MRS Bulletin 33: 21-26.

6. Wu Z, Zhao D (2011) Ordered mesoporous materials as adsorbents. Chemical Communications 47: 3332-3338.

7. Bailey SE, Olin TJ, Bricka RM, Adrian DD (1999) A review of potentially low-cost sorbents for heavy metals. Water Research 33: 2469-2479.

8. Netzer A, Hughes DE (1984) Adsorption of copper, lead and cobalt by activated carbon. Water Research 18: $927-$ 933.

9. G'omez Lahoz C, Garcia Herruzo F, Rodriguez Maroto JM, Rodriguez JJ (1993) Cobalt (II) removal from water by chemical reduction with sodium borohydride. Water $\mathrm{Re}-$ search 27: 985-992.

10. Stellman J, Mc Cann M (1998) Encyclopedia of Occupational Health and Safety. International Labour Office Geneva 3.

11. Pendergast MM, Hoek EM (2011) A review of water treatment membrane nanotechnologies. Energy and Environmental Science 4: 1946-1971.

12. Hai-Wei Liang, Xiang Cao, Wen-Jun Zhang, Hong-Tao Lin, Fei Zhou, et al. (2011) Robust and highly efficient free standing carbonaceous nanofiber membranes for water purification. Advanced Functional Materials 21: 3851-3858.

13. Yezhuo Liu, Zhangxiong Wu, Xin Chen, Zhengzhong Shao, Huanting Wange (2012) A hierarchical adsorption material by incorporating mesoporous carbon into macroporous chitosan membranes. Journal of Materials Chemistry 22: 11908-11911.

14. Cadotte J, Forester R, Kim M, Petersen R, Stocker T (1988) Nanofiltration membranes broaden the use of membrane separation technology. Desalination 70: 77-88.

15. Jackson EA, Hillmyer MA (2010) Nanoporous membranes derived from block copolymers from drug delivery to water filtration. ACS Nano 4: 3548-3553.

16. Dijkstra HP, van Klink GP, van Koten G (2002) The use of ultra-and nanofiltration techniques in homogeneous catalyst recycling. Acc Chem Res 35: 798-810.

17. Celin S, Pierre S, Pirree RB, Benoit B (2012) Hybrid membrane processes using activated carbon treatment for drinking water: A review. Journal of Membrane Science 411-412: 1-12.

18. Panpan W, Jun M, Fengmei S, Yuxin M, Zhenghui W (2013) Behaviors and effects of differing dimensional nanomaterials in water Filtration membranes through the classi- 
cal phase inversion process: A review. Industrial and Engineering Chemistry Research 52: 10355-10363.

19. Brian WS, Jeremy JH, Matthew DM, Merlin LB (2003) UItrathin multilayered polyelectrolyte films as nanofiltration membranes. Langmuir 19: 7038-7042.

20. Sherif ES, Ahmad S, Awual MR, Moataz M (2011) Large three-dimensional mesocage pores tailoring silica nanotubes as membrane filters Nanofiltration and permeation flux of proteins. Journal of Materials Chemistry 21: 5593-5603.

21. Bin Zhao, Zhang Lei, Xianying Wang, Junhe Yang, Tang Zhi-hong, et al. (2011) Research progress in nanofiltration membrane based on carbon nanotubes. New Carbon Materials 26: 321-327.

22. Jelena S, Johan E Ten El, Dave HA (2004) A microporous titania membrane for nanofiltration and pervaporation. Advanced Materials 16: 1546-1550.

23. Choi W, Lahiri I, Seelaboyina R, Kang YS (2010) Synthesis of graphene and its applications: A review. Journal Critical Reviews in Solid State and Materials Sciences 35: 52-71.

24. Stoller MD, Park S, Zhu Y, An J, Ruoff RS, et al. (2008) Graphene-based ultracapacitors. Nano Lett 8: 3498-3502.

25. Tan LL, Chai SP, Mohamed AR (2012) Synthesis and applications of graphene-based $\mathrm{TiO} 2$ photocatalysts. Chem Sus Chem 5: 1868-1882.

26. Balandin AA, Ghosh S, Bao W, Calizo I, Teweldebrhan D, et al. (2008) Superior thermal conductivity of single-layer grapheme. Nano Lett 8: 902-907.

27. KS Novoselov, AK Geim, SV Morozov, D Jiang, Y Zhang, et al. (2004) Electric field effect in atomically thin carbon films. Science 306: 666-669

28. Wang N, Zhang Y, Zhu F, Li J, Liu S, et al. (2014) Adsorption of soluble oil from water to graphene. Environ Sci Pollut Res Int 21: 6495-6505.

29. Yan-Ping Chang, Cui-Ling Ren, Ji-Chun Qu, Xing-Guo Chen (2012) Preparation and characterization of Fe3O4/ graphene nanocomposite and investigation of its adsorption performance for aniline and p-chloroaniline. Applied Surface Science 261: 504-509.

30. Ziyauddin Khan, Tridip Ranjan Chetia, Anil Kumar Vardhaman, Dipankar Barpuzary, Chivukula V Sastria, et al. (2012) Visible light assisted photocatalytic hydrogen generation and organic dye degradation by Cd S-metal oxide hybrids in presence of graphene oxide. RSC Advances 2: 12122-12128.

31. Wenbo L, Yonglan L, Guohui C, Xuping S (2011) Synthesis of functional SiO2-coated graphene oxide nanosheets decorated with $\mathrm{Ag}$ nanoparticles for $\mathrm{H} 2 \mathrm{O} 2$ and glucose detection. Biosensors and Bioelectronics 26: 4791-4797.

32. Dong Wang, Lei Wang, Xinyi Dong, Zhun Shi, Jian Jin (2012) Chemically tailoring graphene oxides into fluorescent nanosheets for Fe3+ ion detection. Carbon 50: 2147-2154.

33. Xiang Zhang, Chong Cheng, Jing Zhao, Lang Ma, Shudong Sun, et al. (2013) Polyethersulfone enwrapped graphene oxide porous particles for water treatment. Chemical Engineering Journal 215-216: 72-81.

34. Mills A, Le Hunte S (1997) An overview of semiconductor photocatalysis. Journal of Photochemistry and Photobiology A Chemistry 108: 1-35.

35. Daneshvar N, Salari D, Alireza Kh (2003) Photocatalytic degradation of azo dye acid red 14 in water: Investigation of the effect of operational parameters. Journal of Photo- chemistry and Photobiology A Chemistry 157: 111-116.

36. Daneshvar N, Salari D, Alireza Kh (2004) Photocatalytic degradation of azo dye acid red 14 in water on $\mathrm{ZnO}$ as an alternative catalyst to TiO2. Journal of Photochemistry and Photobiology A Chemistry 162: 317-322.

37. Cheng XF, Leng WH, Liu DP, Zhang JQ, Cao C N (2007) Enhanced photoelectrocatalytic performance of Zndoped WO3 photocatalysts for nitrite ions degradation under visible light. Chemosphere 68: 1976-1984.

38. Jing D, Guo L (2007) WS2 sensitized mesoporous TiO2 for efficient photocatalytic hydrogen production from water under visible light irradiation. Catalysis Communications 8: 795-799.

39. Bandara J, Klehm U, Kiwi J (2007) Raschig rings-Fe2O3 composite photocatalyst activate in the degradation of 4-chlorophenol and Orange II under daylight irradiation. Applied Catalysis B Environmental 76: 73-81.

40. Teramura K, Tanaka T, Kani M, Hosokawa T, Funabiki T (2004) Selective photo-oxidation of neat cyclohexane in the liquid hase over V2O5/AI2O3. Journal of Molecular Catalysis A Chemical 208: 299-305.

41. Zhai Y, Zhang S, Pang H (2007) Preparation Characterization and photocatalytic activity of $\mathrm{CeO} 2$ nanocrystalline using ammonium bicarbonate as precipitant. Materials Letters 61: 1863-1866.

42. Kanade KG, Baeg JO, Mulik UP, Amalnerkar DP, Kale BB (2006) Nano-CdS by polymer-inorganic solid-state reaction: Visible light pristine photocatalyst for hydrogen generation. Materials Research Bulletin 41: 2219-2225.

43. Torres CL, Mart'i, Kho R, Mian Ol, Mehra RK (2001) Efficient photocatalytic degradation of environmental pollutants with mass-produced ZnS nanocrystals. Journal of Colloid and Interface Science 240: 525-532.

44. Chen D, Zhang H, Liu Y, Li J (2013) Graphene and its derivatives for the development of solar cells, photoelectrochemical and photocatalytic applications. Energy \& Environmental Science 6: 1362-1387.

45. AMás A, Di W (2013) Photoelectrochemical Properties of Graphene and Its Derivatives. Nanomaterials 3: 325-356.

46. Richards R (2006) Surface and Nanomolecular Catalysis. CRC Press/Taylor \& Francis Group.

47. Qin J, Zhang X, Xue Y, Kittiwattanothai N, Pongsakorn Kongsittikul, et al. (2014) A facile synthesis of nanorods of $\mathrm{ZnO} /$ graphene oxide composites with enhanced photocatalytic activity. Applied Surface Science 321: 226-232.

48. Moussa H, Girot E, Mozet K, Alem H, Medjahdi G, et al. (2016) $\mathrm{ZnO}$ rods/reduced graphene oxide composites prepared viaa solvothermal reaction for efficient sunlight0-driven photocatalysis. Applied Catalysis B Environmental 185: 11-21.

49. Zhou X, Shi T, Zhou H (2012) Hydrothermal preparation of ZnO-reduced graphene oxide hybrid with high performance in photocatalytic degradation. Applied Surface Science 258: 6204-6211.

50. Hummers WS, Offeman RE (1958) Preparation of Graphitic Oxide. Journal of the American Chemical Society 80: 13391339.

51. Gao P, Liu J, Lee S, Zhang T, Sun DD (2012) High quality graphene oxide-CdS-Pt nanocomposites for efficient photocatalytic hydrogen evolution. Journal of Materials Chemistry 22: 2292-2298.

52. Li J, Jeong H, Lee K, Park JY, Ahn YH, et al. (2010) Reduc- 
tion of functionalized graphite oxides by trioctylphosphine in non-polar organic solvents. Carbon 48: 2282-2289.

53. Marcano DC, Kosynkin DV, Berlin JM, Sinitskii A, Sun Z, et al. (2010) Improved synthesis of graphene oxide. ACS Nano 4: 4806-4814.

54. Moazzami Gudarzi M, Sharif F (2012) Enhancement of dispersion and bonding of graphene polymer through wet transfer of functionalized graphene oxide. eXPRESS Polymer Letters 6: 1017-1031.

55. Sepideh P, Mohammad Reza V, Alimorad R (2017) Investigating the effect of SiO2-graphene oxide hybrid as inorganic nanofiller on corrosion protection properties of epoxy coatings. Surface \& Coatings Technology 311: 282-294.

56. Woltornist SJ, Oyer AJ, Carrillo JMY, Dobrynin AV, Adamson DH (2013) Conductive thin films of pristine graphene by solvent interface trapping. ACS Nano 7: 7062-7066.

57. Ferrari AC, Meyer JC, Scardaci V, Casiraghi C, Lazzeri M, et al. (2006) Raman spectrum of graphene and graphene layers. Phys Rev Lett 97: 187401-187404.

58. M. Padaki, R. Surya Murali, M.S. Abdullah, N. Misdana, A. Moslehyania, et al. (2015) Membrane technology enhancement in oil-water separation: A review. Desalination 357: 197-207.

59. Mansourizadeh A, Javadi Azad A (2014) Preparation of blend polyethersulfone/cellulose acetate/polyethylene glycol asymmetric membranes for oil-water separation. Journal of Polymer Research 21: 1-9.

60. Li F, Soyi C, Gahee O, Tae SS (2012) Three-Dimensional Graphene Oxide Nanostructure for Fast and Efficient Water-Soluble Dye Removal. ACS Appl Mater Interfaces 4: 922-927.

61. Lulu F, Chuannan LU, Min S, Xiangjun L, Fuguang L, et al. (2012) Preparation of novel magnetic chitosan/graphene oxide composite as effective adsorbents toward methylene blue. Bioresour Technol 114: 703-706.

62. Tonghao L, Li Y, Du Q, Jiankun S, Yuqin J, et al. (2012) Adsorption of methylene blue from aqueous solution by graphene. Colloids Surf B Biointerfaces 90: 197-203.

63. Lulu F, Chuannan L, Min S, Huamin Q, Xiangjun L (2013) Synthesis of magnetic- $\beta$-cyclodextrin-chitosan/graphene oxide as nanoadsorbent and its application in dye adsorption and removal. Colloids Surf B Biointerfaces 103: 601-607.

64. Hem RP, Chan Hee Park, Pashupati P, Leonard D T, Dai $S$ L, et al. (2013) ZnO micro flower assembled on reduced graphene sheet with high photocatalytic activity for removal of pollutant. Powder Technology 235: 853-858.

65. Jiaqian Q, Xinyu Z, Chengwu Y, Meng C, Ma M, et al. (2017) Metallurgy, ZnO microspheres-reduced graphene oxide nanocomposite for photocatalytic degradation of methylene blue dye. Applied Surface Science 392: 196-203.

66. Fang F, Konga L, Huang J, Wua S, Zhang K, et al. (2014) Removal of cobalt ions from aqueous solution by an amination graphene oxide nanocomposite. J Hazard Mater 270: 1-10.

67. Chaohui R, Longfei Z, Yelin Q, Chen X, Xiaobo Z, et al. (2015) Synthesis of porphyrin sensitized TiO2/graphene and its photocatalytic property under visible light. Materials Letters 141: 362-365.

68. Chao X, Aiju C, Yuelian X, Xianzhi F (2013) Graphene oxide-TiO2 composite filtration membranes and their potential application for water purification. Carbon 62: 465-471.

69. Peng G, Zhaoyang L, Minghang T, Darren D S, Wunjern
N (2013) Multifunctional graphene oxide-TiO2 microsphere hierarchical membrane for clean water production. Applied Catalysis B Environmental 138-139: 17-25.

70. Yong G, Meng H, Baoxia M (2014) Membrane surface modification with TiO2-graphene oxide for enhanced photocatalytic performance. Journal of Membrane Science 455: 349-356.

71. Elahe D, Roshanak RK, Homayon Ahmad P, Majid P (2017) Efficiency of Polymeric Membrane Graphene Oxide-TiO2 for Removal of Azo Dye. Journal of Chemistry 2017: 13.

72. Ping N, Jingcheng H (2013) Photocatalytic degradation of methyl orange by titanium dioxide-decatungstate nanocomposite films supported on glass slides. Colloids and Surfaces A Physicochemical and Engineering Aspects 431: 127-132.

73. Simona F, Daniele DA, Sebania L, Isabella N, Vassiliki K, et al. (2015) Graphene oxide and titania hybrid Nafion membranes for efficient removal of methyl orange dye from water. Carbon 82: 489-499.

74. Chrysoula PA, Sergio MT, Vlassis L, George ER, Luisa M, et al. (2014) Prototype composite membranes of partially reduced graphene oxide/TiO2 for photocatalytic ultrafiltration water treatment under visible light. Applied Catalysis $B$ Environmental 158-159: 361-372.

75. Song B, Xiaoping S, Xin Z, Yang L, Guoxing Z, et al. (2012) One-pot solvothermal preparation of magnetic reduced graphene oxide-ferrite hybrids for organic dye removal. Carbon 50: 2337-2346.

76. Lunhong A, Chunying Z, Zhonglan C (2011) Removal of methylene blue from aqueous solution by a solvothermal-synthesized graphene/magnetite composite. Journal of Hazardous Materials 192: 1515-1524.

77. Ramdahl T, Alfheim I, Bjorseth A (1982) Nitrated polycyclic aromatic-hydrocarbons in urban air particles. Environ Sci Technol 16: 861-865.

78. Freemann DJ, Cattell CR (1990) Woodburning as a source of atmospheric polycyclic aromatic hydrocarbons. Environ Sci Technol 24: 1581-1585.

79. Tan YL, Quanci JF, Borys RD (1992) Polycyclic aromatic hydrocarbons in smoke particles from wood and duff burning. Atmospheric Environment Part A General Topics 26: 1177-1181.

80. Ainhoa RC, Ricardo AT, Gustavo A P (2014) Removal of polycyclic aromatic hydrocarbons in aqueous environment by chemical treatments: A review. Sci Total Environ 478: 201-225.

81. Mahdie S, Alireza K, Vahid V (2015) Effect of reduced graphene oxide/TiO2 nanocomposite with different molar ratios on the performance of PVDF ultrafiltration membranes. Separation and Purification Technology 140: 3242.

82. Na W, Yuchang Z, Fuzhen Z, Jingyi L, Shuaishuai L, et al. (2014) Adsorption of soluble oil from water to graphene. Environ Sci Pollut Res Int 21: 6495-6505.

83. Yi XS, Yu SL, Shi WX, Sun N, Jin LM, et al. (2011) The influence of important factors on ultrafiltration of oil/water emulsion using PVDF membrane modified by nano-sized TiO2/AI2O3. Desalination 281: 179-184.

84. Yuqing Z, Fanglong L, Yiren L, Lili Z, Lixin S (2013) Investigation of phosphorylated $\mathrm{TiO} 2-\mathrm{SiO} 2$ particles/polysulfone composite membrane for wastewater treatment. Desalination 324: 118-126. 
85. Jamshidi Gohari R, Halakoo E, Lau WJ, Kassim MA, Matsuuraac T, et al. (2014) Novel polyethersulfone (PES)/hydrous manganesedioxide (HMO) mixed matrix membranes with improved anti-fouling properties for oily wastewater treatment process. RSC Adv 4: 17587-17596.

86. Vahid V, Sayed Siavash M, Rostam M, Sirus Z, Bandar A (2012) Novel antibifouling nanofiltration polyethersulfone membrane fabricated from embedding TiO2 coated multiwalled carbon nanotubes. Separation and Purification Technology 90: 69-82.

87. Ahmad AL, Majid MA, BS Ooi (2011) Functionalized PSf/ $\mathrm{SiO} 2$ nanocomposite membrane for oil-in-water emulsion separation. Desalination 268: 266-269.

88. Mahendra K, Zahra G, Anne M, Kieran N, Mathias U, et al. (2016) Preparation and characterization of low fouling novel hybrid ultrafiltration membranes based on the blends of GO-TiO2 nanocomposite and polysulfone for humic acid removal. Journal of Membrane Science 506: 38-49.

89. Huiqing W, Beibei Tang, Peiyi W (2014) Development of novel SiO2-GO nanohybrid/polysulfone membrane with enhanced performance. Journal of Membrane Science 451: 94-102.

90. Zonghua W, Hairong Y, Jianfei X, Feifei Z, Feng Li, et al. (2012) Novel GO-blended PVDF ultrafiltration membranes. Desalination 2999: 50-54.

91. Zhong-KL, Wan-Zhong L, Wei M, Xi Y, Ya-JG (2016) Preparation and properties of PVDF/SiO2@GO nanohybridmembranes via thermally induced phase separation method. Journal of Membrane Science 511: 151-161.

92. Wenbo Lu, Yonglan Luo, Guohui C, Xuping S (2011) Synthesis of functional $\mathrm{SiO} 2$-coated graphene oxide nanosheets decorated with Ag nanoparticles for $\mathrm{H} 2 \mathrm{O} 2$ and glucose detection. Biosensors and Bioelectronics 26: 4791-4797.

93. Liang Yu, Yatao Zhang, Bing Zhang, Jindun Liu, Haoqin Zhang, et al. (2013) Preparation and characterization of HPEIGO/PES ultrafiltration membrane with antifouling and antibacterial properties. Journal of Membrane Science 447: 452-462.

94. Alireza Heidari, Christopher Brown (2015) Study of composition and morphology of cadmium oxide (CdO) nanoparticles for eliminating cancer cells. Journal of Nanomedicine Research 2: 20.

95. Alireza Heidari, Christopher Brown (2015) Study of surface morphological, phytochemical and structural characteristics of rhodium (III) oxide $\left(\mathrm{Rh}_{2} \mathrm{O}_{3}\right)$ nanoparticles. International Journal of Pharmacology, Phytochemistry and Ethnomedicine 1: 15-19.

96. Alireza Heidari (2016) An experimental biospectroscopic study on seminal plasma in determination of semen quality for evaluation of male infertility. Int J Adv Technol 7: e007.

97. Alireza Heidari (2016) Extraction and preconcentration of $\mathrm{N}$-tolyl-sulfonyl-phosphoramid-saeure-dichlorid as an anti-cancer drug from plants: A pharmacognosy study. J Pharmacogn Nat Prod 2: e103.

98. Alireza Heidari (2016) A thermodynamic study on hydration and dehydration of DNA and RNA-amphiphile complexes. J Bioeng Biomed Sci S: 006.

99. Alireza Heidari (2016) Computational studies on molecular structures and carbonyl and ketene groups effects of singlet and triplet energies of azidoketene $\mathrm{O}=\mathrm{C}=\mathrm{CH}-\mathrm{NNN}$ and isocyanatoketene $\mathrm{O}=\mathrm{C}=\mathrm{CH}-\mathrm{N}=\mathrm{C}=\mathrm{O}$. J Appl Computat Math 5: e142.

100. Alireza Heidari (2016) Study of irradiations to enhance the induces the dissociation of hydrogen bonds between pep- tide chains and transition from helix structure to random coil structure using ATR-FTIR, raman and ${ }^{~} \mathrm{HNMR}$ spectroscopies. J Biomol Res Ther 5: e146.

101. Alireza Heidari (2016) Future prospects of point fluorescence spectroscopy, fluorescence imaging and fluorescence endoscopy in photodynamic therapy (PDT) for cancer cells. J Bioanal Biomed 8: e135.

102. Alireza Heidari (2016) A bio-spectroscopic study of DNA density and color role as determining factor for absorbed irradiation in cancer cells. Adv Cancer Prev 1: e102.

103. Alireza Heidari (2016) Manufacturing process of solar cells using cadmium oxide ( $\mathrm{CdO}$ ) and rhodium (III) oxide $\left(\mathrm{Rh}_{2} \mathrm{O}_{3}\right)$ nanoparticles. J Biotechnol Biomater 6: e125.

104. Alireza Heidari (2016) A novel experimental and computational approach to photobiosimulation of telomeric DNA/ RNA: A biospectroscopic and photobiological study. J Res Development 4: 144.

105. Alireza Heidari (2016) Biochemical and pharmacodynamical study of microporous molecularly imprinted polymer selective for vancomycin, teicoplanin, oritavancin, telavancin and dalbavancin binding. Biochem Physiol 5: e146.

106. Alireza Heidari (2016) Anti-cancer effect of UV irradiation at presence of cadmium oxide $(\mathrm{CdO})$ nanoparticles on DNA of cancer cells: A photodynamic therapy study. Arch Cancer Res 4: 1.

107. Alireza Heidari (2016) Biospectroscopic study on multi-component reactions (MCRs) in two A-type and B-type conformations of nucleic acids to determine ligand binding modes, binding constant and stability of nucleic acids in cadmium oxide ( $\mathrm{CdO}$ ) nanoparticles-nucleic acids complexes as anti-cancer drugs. Arch Cancer Res 4: 2.

108. Alireza Heidari (2016) Simulation of temperature distribution of DNA/RNA of human cancer cells using time-dependent bio-heat equation and Nd: YAG lasers. Arch Cancer Res 4: 2.

109. Alireza Heidari (2016) Quantitative structure-activity relationship (QSAR) approximation for cadmium oxide (CdO) and rhodium (III) oxide $\left(\mathrm{Rh}_{2} \mathrm{O}_{3}\right)$ nanoparticles as anti-cancer drugs for the catalytic formation of proviral DNA from viral RNA using multiple linear and non-linear correlation approach. Ann Clin Lab Res 4: 1.

110. Alireza Heidari (2016) Biomedical study of cancer cells DNA therapy using laser irradiations at presence of intelligent nanoparticles. J Biomedical Sci 5: 2.

111. Alireza Heidari (2016) Measurement the amount of vitamin $D_{2}$ (ergocalciferol), vitamin $D_{3}$ (cholecalciferol) and absorbable calcium $\left(\mathrm{Ca}^{2+}\right)$, iron (II) $\left(\mathrm{Fe}^{2+}\right)$, magnesium $\left(\mathrm{Mg}^{2+}\right)$, phosphate $\left(\mathrm{PO}_{4}^{-}\right)$and zinc $\left(\mathrm{Zn}^{2+}\right)$ in apricot using high-performance liquid chromatography (HPLC) and spectroscopic techniques. J Biom Biostat 7: 292.

112. Alireza Heidari (2016) Spectroscopy and quantum mechanics of the helium dimer $\left(\mathrm{He}_{2}^{+}\right)$, neon dimer $\left(\mathrm{Ne}_{2}{ }^{+}\right.$, argon dimer $\left(\mathrm{Ar}_{2}^{+}\right)$, krypton dimer $\left(\mathrm{Kr}_{2}^{+}\right)$, xenon dimer $\left(\mathrm{Xe}_{2}^{+}\right)$, radon dimer $\left(\mathrm{Rn}_{2}^{+}\right)$and ununoctium dimer $\left(\mathrm{UuO}_{2}^{+}\right.$molecular cations. Chem Sci J 7: e112.

113. Alireza Heidari (2016) Human toxicity photodynamic therapy studies on DNA/RNA complexes as a promising new sensitizer for the treatment of malignant tumors using bio-spectroscopic techniques. J Drug Metab Toxicol 7: e129.

114. Alireza Heidari (2016) Novel and stable modifications of intelligent cadmium oxide $(\mathrm{CdO})$ nanoparticles as anti-cancer drug in formation of nucleic acids complexes for human cancer cells treatment. Biochem Pharmacol (Los 
Angel) 5: 207.

115. Alireza Heidari (2016) A combined computational and QM/ MM molecular dynamics study on boron nitride nanotubes (BNNTs), amorphous boron nitride nanotubes (a-BNNTs) and hexagonal boron nitride nanotubes (h-BNNTs) as hydrogen storage. Struct Chem Crystallogr Commun 2: 1.

116. Alireza Heidari (2016) Pharmaceutical and analytical chemistry study of cadmium oxide (CdO) nanoparticles synthesis methods and properties as anti-cancer drug and its effect on human cancer cells. Pharm Anal Chem Open Access 2: 113.

117. Alireza Heidari (2016) A chemotherapeutic and biospectroscopic investigation of the interaction of double-standard DNA/RNA-binding molecules with cadmium oxide (CdO) and rhodium (III) oxide $\left(\mathrm{Rh}_{2} \mathrm{O}_{3}\right)$ nanoparticles as anti-cancer drugs for cancer cells treatment. Chemo Open Access 5: e129.

118. Alireza Heidari (2016) Pharmacokinetics and experimental therapeutic study of DNA and other biomolecules using lasers: Advantages and applications. J Pharmacokinet Exp Ther 1: e005

119. Alireza Heidari (2016) Determination of ratio and stability constant of DNA/RNA in human cancer cells and cadmium oxide ( $\mathrm{CdO}$ ) nanoparticles complexes using analytical electrochemical and spectroscopic techniques. Insights Anal Electrochem 2: 1

120. Alireza Heidari (2016) Discriminate between antibacterial and non-antibacterial drugs artificial neutral networks of a multilayer perceptron (MLP) type using a set of topological descriptors. J Heavy Met Toxicity Dis 1: 2.

121. Alireza Heidari (2016) Combined theoretical and computational study of the belousov-zhabotinsky chaotic reaction and curtius rearrangement for synthesis of mechlorethamine, cisplatin, streptozotocin, cyclophosphamide, melphalan, busulphan and BCNU as anti-cancer drugs. Insights Med Phys 1: 2.

122. Alireza Heidari (2016) A translational biomedical approach to structural arrangement of amino acids' complexes: A combined theoretical and computational study. Transl Biomed 7: 2

123. Alireza Heidari (2016) Ab initio and density functional theory (DFT) studies of dynamic NMR shielding tensors and vibrational frequencies of DNA/RNA and cadmium oxide $(\mathrm{CdO})$ nanoparticles complexes in human cancer cells. $J$ Nanomedine Biotherapeutic Discov 6: e144.

124. Alireza Heidari (2016) Molecular dynamics and monte-carlo simulations for replacement sugars in insulin resistance, obesity, LDL cholesterol, triglycerides, metabolic syndrome, type 2 diabetes and cardiovascular disease: A glycobiological study. J Glycobiol 5: e111.

125. Alireza Heidari (2016) Synthesis and study of 5-[(phenylsulfonyl)amino]-1,3,4-thiadiazole-2- sulfonamide as potential anti-pertussis drug using chromatography and spectroscopy techniques. Transl Med (Sunnyvale) 6: e137.

126. Alireza Heidari (2016) Nitrogen, oxygen, phosphorus and sulphur heterocyclic anti-cancer nano drugs separation in the supercritical fluid of ozone $\left(\mathrm{O}_{3}\right)$ using soave-redlichkwong (SRK) and pang-robinson (PR) equations. Electronic J Biol 12: 4.

127. Alireza Heidari (2016) An analytical and computational infrared spectroscopic review of vibrational modes in nucleic acids. Austin J Anal Pharm Chem 3: 1058.
128. Alireza Heidari, Christopher Brown (2016) Phase, composition and morphology study and analysis of Os- $\mathrm{Pd} / \mathrm{HfC}$ nanocomposites. Nano Res Appl 2: 1.

129. Alireza Heidari, Christopher Brown (2016) Vibrational spectroscopic study of intensities and shifts of symmetric vibration modes of ozone diluted by cumene. International Journal of Advanced Chemistry 4: 5-9.

130. Alireza Heidari (2016) Study of the role of anti-cancer molecules with different sizes for decreasing corresponding bulk tumor multiple organs or tissues. Arch Can Res 4: 2.

131. Alireza Heidari (2016) Genomics and proteomics studies of zolpidem, necopidem, alpidem, saripidem, miroprofen, zolimidine, olprinone and abafungin as anti-tumor, peptide antibiotics, antiviral and central nervous system (CNS) drugs. J Data Mining Genomics \& Proteomics 7: e125.

132. Alireza Heidari (2016) Pharmacogenomics and pharmacoproteomics studies of phosphodiesterase-5 (PDE5) inhibitors and paclitaxel albumin-stabilized nanoparticles as sandwiched anti-cancer nano drugs between two DNA/ RNA molecules of human cancer cells. J Pharmacogenomics Pharmacoproteomics 7: e153.

133. Alireza Heidari (2016) Biotranslational medical and biospectroscopic studies of cadmium oxide (Cdo) nanoparticles-DNA/RNA straight and cycle chain complexes as potent anti-viral, anti-tumor and anti-microbial drugs: $A$ clinical approach. Transl Biomed 7: 2.

134. Alireza Heidari (2016) A comparative study on simultaneous determination and separation of adsorbed cadmium oxide (CdO) nanoparticles on DNA/RNA of human cancer cells using biospectroscopic techniques and dielectrophoresis (DEP) method. Arch Can Res 4: 2.

135. Alireza Heidari (2016) Cheminformatics and system chemistry of cisplatin, carboplatin, nedaplatin, oxaliplatin, heptaplatin and lobaplatin as anti-cancer nano drugs: A combined computational and experimental study. J Inform Data Min 1: 3 .

136. Alireza Heidari (2016) Linear and non-linear quantitative structure-anti-cancer-activity relationship (QSACAR) study of hydrous ruthenium (IV) oxide $\left(\mathrm{RuO}_{2}\right)$ nanoparticles as non-nucleoside reverse transcriptase inhibitors (NNRTIS) and anti-cancer nano drugs. J Integr Oncol 5: e110.

137. Alireza Heidari (2016) synthesis, characterization and biospectroscopic studies of cadmium oxide $(\mathrm{CdO})$ nanoparticles- nucleic acids complexes absence of soluble polymer as a protective agent using nucleic acids condensation and solution reduction method. J Nanosci Curr Res 1: e101.

138. Alireza Heidari (2016) Coplanarity and collinearity of 4'-dinonyl-2,2'-bithiazole in one domain of bleomycin and pingyangmycin to be responsible for binding of cadmium oxide $(\mathrm{CdO})$ nanoparticles to DNA/RNA bidentate ligands as anti-tumor nano drug. Int J Drug Dev \& Res 8: 007-008.

139. Alireza Heidari (2016) A pharmacovigilance study on linear and non-linear quantitative structure (chromatographic) retention relationships (QSRR) models for the prediction of retention time of anti-cancer nano drugs under synchrotron radiations. J Pharmacovigil 4: e161.

140. Alireza Heidari (2016) Nanotechnology in preparation of semipermeable polymers. J Adv Chem Eng 6: 157.

141. Alireza Heidari (2016) A gastrointestinal study on linear and non-linear quantitative structure (chromatographic) retention relationships (QSRR) models for analysis 5-aminosalicylates nano particles as digestive system nano drugs under synchrotron radiations. J Gastrointest Dig 
Syst 6: e119.

142. Alireza Heidari (2016) DNA/RNA fragmentation and cytolysis in human cancer cells treated with diphthamide nano particles derivatives. Biomedical Data Mining 5: e102.

143. Alireza Heidari (2016) A successful strategy for the prediction of solubility in the construction of quantitative structure-activity relationship (QSAR) and quantitative structure-property relationship (QSPR) under synchrotron radiations using genetic function approximation (GFA) algorithm. J Mol Biol Biotechnol 1: 1.

144. Alireza Heidari (2016) Computational study on molecular structures of C20, C60, C240, C540, C960, C2160 and C3840 fullerene nano molecules under synchrotron radiations using fuzzy logic. J Material Sci Eng 5: 282.

145. Alireza Heidari (2016) Graph theoretical analysis of zigzag polyhexamethylene biguanide, polyhexamethylene adipamide, polyhexamethylene biguanide gauze and polyhexamethylene biguanide hydrochloride (PHMB) boron nitride nanotubes (BNNTS), amorphous boron nitride nanotubes (a-BNNTs) and hexagonal boron nitride nanotubes (h-BNNTs). J Appl Computat Math 5: e143.

146. Alireza Heidari (2016) The Impact of High Resolution Imaging on Diagnosis. Int J Clin Med Imaging 3: 1000e101.

147. Alireza Heidari (2016) A comparative study of conformational behavior of isotretinoin (13-cis retinoic acid) and tretinoin (all-trans retinoic acid (ATRA)) nano particles as anti-cancer nano drugs under synchrotron radiations using hartree-fock (HF) and density functional theory (DFT) methods. Insights in Biomed 1: 2.

148. Alireza Heidari (2016) Advances in logic, operations and computational mathematics. J Appl Computat Math 5: 5.

149. Alireza Heidari (2016) Mathematical equations in predicting physical behavior. J Appl Computat Math 5: 5.

150. Alireza Heidari (2016) Chemotherapy a last resort for cancer treatment. Chemo Open Access 5: 4.

151. Alireza Heidari (2016) Separation and pre-concentration of metal cations-DNA/RNA chelates using molecular beam mass spectrometry with tunable vacuum ultraviolet (VUV) synchrotron radiation and various analytical methods. Mass Spectrom Purif Tech 2: e101.

152. Alireza Heidari (2016) Yoctosecond quantitative structure-activity relationship (QSAR) and quantitative structure-property relationship (QSPR) under synchrotron radiations studies for prediction of solubility of anti-cancer nano drugs in aqueous solutions using genetic function approximation (GFA) algorithm. Insight Pharm Res 1: 1.

153. Alireza Heidari (2016) Cancer risk prediction and assessment in human cells under synchrotron radiations using quantitative structure activity relationship (QSAR) and quantitative structure properties relationship (QSPR) studies. Int J Clin Med Imaging 3: 516.

154. Alireza Heidari (2016) A novel approach to biology. Electronic J Biol 12: 4

155. Alireza Heidari (2016) Innovative biomedical equipment's for diagnosis and treatment. J Bioengineer \& Biomedical Sci 6: 1

156. Alireza Heidari (2016) Integrating precision cancer medicine into healthcare, medicare reimbursement changes and the practice of oncology: Trends in oncology medicine and practices. J Oncol Med \& Pract 1: 1.

157. Alireza Heidari (2016) Promoting convergence in biomedical and biomaterials sciences and silk proteins for bio- medical and biomaterials applications: An introduction to materials in medicine and bioengineering perspectives. $J$ Bioengineer \& Biomedical Sci 6: 1-2.

158. Alireza Heidari (2017) X-ray fluorescence and x-ray diffraction analysis on discrete element modeling of nano powder metallurgy processes in optimal container design. J Powder Metall Min 6: 1-2.

159. Alireza Heidari (2017) Biomolecular spectroscopy and dynamics of nano-sized molecules and clusters as cross-linking-induced anti-cancer and immune-oncology nano drugs delivery in DNA/RNA of human cancer cells' membranes under synchrotron radiations: A payload-based perspective. Arch Chem Res 1: 2.

160. Alireza Heidari (2017) Deficiencies in repair of double-standard DNA/RNA binding molecules identified in many types of solid and liquid tumors oncology in human body for advancing cancer immunotherapy using computer simulations and data analysis: Number of mutations in a synchronous tumor varies by age and type of synchronous cancer. J Appl Bioinforma Comput Biol 6: 1.

161. Alireza Heidari (2017) Electronic coupling among the five nanomolecules shuts down quantum tunneling in the presence and absence of an applied magnetic field for indication of the dimer or other provide different influences on the magnetic behavior of single molecular magnets (SMMs) as qubits for quantum computing. Glob J Res Rev 4: 2.

162. Alireza Heidari (2017) Polymorphism in nano-sized graphene ligand-induced transformation of $\mathrm{Au}_{38}-\mathrm{xAg} / \mathrm{xCu_{x }}(\mathrm{SPh}-\mathrm{tBu})_{24}$ to $\mathrm{Au}_{36}-\mathrm{xAg}_{\mathrm{x}} / \mathrm{xCu}_{\mathrm{x}}(\mathrm{SPh}-\mathrm{tBu})_{24}(\mathrm{x}=1-12)$ nanomolecules for synthesis of $\mathrm{Au}_{144}-\mathrm{xAg}_{\mathrm{x}} / \mathrm{xCu_{x }}\left[(\mathrm{SR})_{60},\left(\mathrm{SC}_{4}\right)_{60},\left(\mathrm{SC}_{6) 60},\left(\mathrm{SC}_{12) 60}\right.\right.\right.$, $(\mathrm{PET})_{60},(\mathrm{p}-\mathrm{MBA})_{60},(\mathrm{~F})_{60},(\mathrm{Cl})_{60},(\mathrm{Br})_{60},(\mathrm{I})_{60},(\mathrm{At})_{60},(\mathrm{Uus})_{60}$ and $\left(\mathrm{SC}_{6} \mathrm{H}_{13}\right)_{60}$ ] nano clusters as anti-cancer nano drugs. J Nanomater Mol Nanotechnol 6: 3.

163. Alireza Heidari (2017) Biomedical resource oncology and data mining to enable resource discovery in medical, medicinal, clinical, pharmaceutical, chemical and translational research and their applications in cancer research. Int $\mathrm{J}$ Biomed Data Min 6: e103.

164. Alireza Heidari (2017) Study of synthesis, pharmacokinetics, pharmacodynamics, dosing, stability, safety and efficacy of olympiada ne nanomolecules as agent for cancerenzymotherapy immunotherapy, chemotherapy, radiotherapy, hormone therapy and targeted therapy under synchrotorn radiation. J Dev Drugs 6: e154.

165. Alireza Heidari (2017) A novel approach to future horizon of top seven biomedical research topics to watch in 2017: Alzheimer's, ebola, hypersomnia, human immunodeficiency virus (HIV), tuberculosis (TB), microbiome/antibiotic resistance and endovascular stroke. J Bioengineer \& Biomedical Sci 7: e127.

166. Alireza Heidari (2017) Opinion on computational fluid dynamics (CFD) technique. Fluid Mech Open Acc 4: 157.

167. Alireza Heidari (2017) Concurrent diagnosis of oncology influence outcomes in emergency general surgery for colorectal cancer and multiple sclerosis (MS) treatment using magnetic resonance imaging (MRI) and $\mathrm{Au}_{329}(\mathrm{SR})_{84}, \quad \mathrm{Au}_{329-\mathrm{x}} \mathrm{Ag}_{\mathrm{x}}(\mathrm{SR})_{84}, \quad \mathrm{Au}_{144}(\mathrm{SR})_{60}, \quad \mathrm{Au}_{68}(\mathrm{SR})_{36}$, $\mathrm{Au}_{30}(\mathrm{SR})_{18}, \quad \mathrm{Au}_{102}(\mathrm{SPh})_{44}, \quad \mathrm{Au}_{38}(\mathrm{SPh})_{24}, \quad \mathrm{Au}_{38}\left(\mathrm{SC}_{2} \mathrm{H}_{4} \mathrm{Ph}\right)_{24}$, $\mathrm{Au}_{21} \mathrm{~S}(\mathrm{SAdm})_{15}, \mathrm{Au}_{36}(\mathrm{pMBA})_{24}$ and $\mathrm{Au}_{25}(\mathrm{pMBA})_{18}$ nano clusters. J Surgery Emerg Med 1: 21.

168. Alireza Heidari (2017) Developmental cell biology in adult stem cells death and autophagy to trigger a preventive allergic reaction to common airborne allergens under synchrotron radiation using nanotechnology for therapeutic 
goals in particular allergy shots (immunotherapy). Cell Biol (Henderson, NV) 6: 1.

169. Alireza Heidari (2017) Changing metal powder characteristics for elimination of the heavy metals toxicity and diseases in disruption of extracellular matrix (ECM) proteins adjustment in cancer metastases induced by osteosarcoma, chondrosarcoma, carcinoid, carcinoma, ewing's sarcoma, fibrosarcoma and secondary hematopoietic solid or soft tissue tumors. J Powder Metall Min 6: 170.

170. Alireza Heidari (2017) Nanomedicine-based combination anti-cancer therapy between nucleic acids and anti-cancer nano drugs in covalent nano drugs delivery systems for selective imaging and treatment of human brain tumors using hyaluronic acid, alguronic acid and sodium hyaluronate as anti-cancer nano drugs and nucleic acids delivery under synchrotron radiation. Am J Drug Deliv 5: 092-096.

171. Alireza Heidari (2017) Clinical trials of dendritic cell therapies for cancer exposing vulnerabilities in human cancer cells'metabolism and metabolomics: New discoveries, unique features inform new therapeutic opportunities, biotech's bumpy road to the market and elucidating the biochemical programs that support cancer initiation and progression. J Biol Med Science 1: e103.

172. Alireza Heidari (2017) The design graphene-based nanosheets as a new nanomaterial in anti-cancer therapy and delivery of chemotherapeutics and biological nano drugs for liposomal anti-cancer nano drugs and gene delivery. Br Biomed Bull 5: 305.

173. Alireza Heidari (2017) Integrative approach to biological networks for emerging roles of proteomics, genomics and transcriptomics in the discovery and validation of human colorectal cancer biomarkers from DNA/RNA sequencing data under synchrotron radiation. Transcriptomics 5: e117.

174. Alireza Heidari (2017) Elimination of the heavy metals toxicity and diseases in disruption of extracellular matrix (ECM) proteins and cell adhesion intelligent nanomolecules adjustment in cancer metastases using metalloenzymes and under synchrotron radiation. Lett Health Biol Sci 2: 1-4.

175. Alireza Heidari (2017) Treatment of breast cancer brain metastases through a targeted nanomolecule drug delivery system based on dopamine functionalized multi-wall carbon nanotubes (MWCNTs) coated with nano graphene oxide (GO) and protonated polyaniline (PANI) in situ during the polymerization of aniline autogenic nanoparticles for the delivery of anti-cancer nano drugs under synchrotron radiation. $\mathrm{Br} \mathrm{J}$ Res 4: 16.

176. Alireza Heidari (2017) Sedative, analgesic and ultrasound-mediated gastrointestinal nano drugs delivery for gastrointestinal endoscopic procedure, nano drug-induced gastrointestinal disorders and nano drug treatment of gastric acidity. Res Rep Gastroenterol 1: 1.

177. Alireza Heidari (2017) Synthesis, pharmacokinetics, pharmacodynamics, dosing, stability, safety and efficacy of orphan nano drugs to treat high cholesterol and related conditions and to prevent cardiovascular disease under synchrotron radiation. J Pharm Sci Emerg Drugs 5: 1.

178. Alireza Heidari (2017) Non-linear compact proton synchrotrons to improve human cancer cells and tissues treatments and diagnostics through particle therapy accelerators with monochromatic microbeams. Cell Immunol Serum Biol 3: 115-119.

179. Alireza Heidari (2017) Design of targeted metal chela- tion therapeutics nanocapsules as colloidal carriers and blood-brain barrier (BBB) translocation to targeted deliver anti-cancer nano drugs into the human brain to treat alzheimer's disease under synchrotron radiation. J Nanotechnol Material Sci 4: 62-66.

180. Ricardo Gobato, Alireza Heidari (2017) Calculations using quantum chemistry for inorganic molecule simulation Be$\mathrm{Li}_{2} \mathrm{SeSi}$. Science Journal of Analytical Chemistry 5: 76-85.

181. Alireza Heidari (2017) Different high-resolution simulations of medical, medicinal, clinical, pharmaceutical and therapeutics oncology of human lung cancer translational anti-cancer nano drugs delivery treatment process under synchrotron and $\mathrm{X}$-ray radiations. $\mathrm{J}$ Med Oncol 1: 1.

182. Alireza Heidari (2017) A modern ethnomedicinal technique for transformation, prevention and treatment of human malignant gliomas tumors into human benign gliomas tumors under synchrotron radiation. Am J Ethnomed 4: 10.

183. Alireza Heidari (2017) Active targeted nanoparticles for anti-cancer nano drugs delivery across the blood-brain barrier for human brain cancer treatment, multiple sclerosis (MS) and alzheimer's diseases using chemical modifications of anti-cancer nano drugs or drug-nanoparticles through zika virus (ZIKV) nanocarriers under synchrotron radiation. J Med Chem Toxicol 2: 1-5.

184. Alireza Heidari (2017) Investigation of medical, medicinal, clinical and pharmaceutical applications of estradiol, mestranol (norlutin), norethindrone (NET), norethisterone acetate (NETA), norethisterone enanthate (NETE) and testosterone nanoparticles as biological imaging, cell labeling, anti-microbial agents and anti-cancer nano drugs in nanomedicines based drug delivery systems for anti-cancer targeting and treatment. Parana Journal of Science and Education 3: 10-19.

185. Alireza Heidari (2017) A comparative computational and experimental study on different vibrational biospectroscopy methods, techniques and applications for human cancer cells in tumor tissues simulation, modeling, research, diagnosis and treatment. Open $\mathrm{J}$ Anal Bioanal Chem 1: 014-020.

186. Alireza Heidari (2017) Combination of DNA/RNA ligands and linear/non-linear visible-synchrotron radiation-driven $\mathrm{N}$ - doped ordered mesoporous cadmium oxide (Cdo) nanoparticles photocatalysts channels resulted in an interesting synergistic effect enhancing catalytic anti-cancer activity. Enz Eng 6: 160.

187. Alireza Heidari (2017) Modern approaches in designing ferritin, ferritin light chain, transferrin, beta-2 transferrin and bacterioferritin-based anti-cancer nano drugs encapsulating nanosphere as DNA-binding proteins from starved cells (DPS). Mod Appro Drug Des 1: 000504.

188. Alireza Heidari (2017) Potency of human interferon $\beta$-1a and human interferon $\beta-1 b$ in enzymotherapy, immunotherapy, chemotherapy, radiotherapy, hormone therapy and targeted therapy of encephalomyelitis disseminate/multiple sclerosis (MS) and hepatitis A, B, C, D, E, F and G virus enter and targets liver cells. J Proteomics Enzymol 6: 1.

189. Alireza Heidari (2017) Transport therapeutic active targeting of human brain tumors enable anti-cancer nanodrugs delivery across the blood-brain barrier (BBB) to treat brain diseases using nanoparticles and nanocarriers under synchrotron radiation. J Pharm Pharmaceutics 4: 1-5.

190. Alireza Heidari, Christopher Brown (2017) Combinatorial therapeutic approaches to DNA/RNA and benzylpeni- 
cillin (Penicillin G), fluoxetine hydrochloride (prozac and sarafem), propofol (diprivan), acetylsalicylic acid (ASA) (aspirin), naproxen sodium (aleve and naprosyn) and dextromethamphetamine nanocapsules with surface conjugated DNA/RNA to targeted nano drugs for enhanced anti-cancer efficacy and targeted cancer therapy using nano drugs delivery systems. Ann Adv Chem 1: 061-069.

191. Alireza Heidari (2017) High-resolution simulations of human brain cancer translational nano drugs delivery treatment process under synchrotron radiation. J Transl Res 1: 1-3.

192. Alireza Heidari (2017) Investigation of anti-cancer nano drugs' effects' trend on human pancreas cancer cells and tissues prevention, diagnosis and treatment process under synchrotron and $x$-ray radiations with the passage of time using mathematica. Current Trends Anal Bioanal Chem 1: 36-41.

193. Alireza Heidari (2017) Pros and cons controversy on molecular imaging and dynamics of double-standard DNA/ RNA of human preserving stem cells-binding nano molecules with androgens/anabolic steroids (AAS) or testosterone derivatives through tracking of Helium-4nucleus (alpha particle) using synchrotron radiation. Arch Biotechnol Biomed 1: 067-100.

194. Alireza Heidari (2017) Visualizing metabolic changes in probing human cancer cells and tissues metabolism using vivo ${ }^{1} \mathrm{H}$ or proton NMR, ${ }^{13} \mathrm{C}$ NMR, ${ }^{15} \mathrm{~N}$ NMR and ${ }^{31} \mathrm{P}$ NMR spectroscopy and self-organizing maps under synchrotron radiation. SOJ Mater Sci Eng 5: 1-6.

195. Alireza Heidari (2017) Cavity ring-down spectroscopy (CRDS), circular dichroism spectroscopy, cold vapour atomic fluorescence spectroscopy and correlation spectroscopy comparative study on malignant and benign human cancer cells and tissues with the passage of time under synchrotron radiation. Enliven: Challenges Cancer Detect Ther 4: e001.

196. Alireza Heidari (2017) Laser spectroscopy, laser-induced breakdown spectroscopy and laser-induced plasma spectroscopy comparative study on malignant and benign human cancer cells and tissues with the passage of time under synchrotron radiation. Int J Hepatol Gastroenterol 3: 079-084.

197. Alireza Heidari (2017) Time-resolved spectroscopy and time-stretch spectroscopy comparative study on malignant and benign human cancer cells and tissues with the passage of time under synchrotron radiation. Enliven: Pharmacovigilance and Drug Safety 4: e001.

198. Alireza Heidari (2017) Overview of the role of vitamins in reducing negative effect of decapeptyl (triptorelin acetate or pamoate salts) on prostate cancer cells and tissues in prostate cancer treatment process through transformation of malignant prostate tumors into benign prostate tumors under synchrotron radiation. Open J Anal Bioanal Chem 1: 021-026.

199. Alireza Heidari (2017) Electron phenomenological spectroscopy, electron paramagnetic resonance (EPR) spectroscopy and electron spin resonance (ESR) spectroscopy comparative study on malignant and benign human cancer cells and tissues with the passage of time under synchrotron radiation. Austin J Anal Pharm Chem 4: 1091.

200. Alireza Heidari (2017) Therapeutic nanomedicine different high-resolution experimental images and computational simulations for human brain cancer cells and tissues using nanocarriers deliver DNA/RNA to brain tumors under synchrotron radiation with the passage of time using mathematica and MATLAB. Madridge J Nano Tech Sci 2: 78-84.
201. Alireza Heidari (2017) A consensus and prospective study on restoring cadmium oxide ( $\mathrm{CdO}$ ) nanoparticles sensitivity in recurrent ovarian cancer by extending the cadmium oxide ( $\mathrm{CdO}$ ) nanoparticles-free interval using synchrotron radiation therapy as antibody-drug conjugate for the treatment of limited-stage small cell diverse epithelial cancers. Cancer Clin Res Rep 1: e001.

202. Alireza Heidari (2017) A Novel and modern experimental imaging and spectroscopy comparative study on malignant and benign human cancer cells and tissues with the passage of time under white synchrotron radiation. Cancer Sci Res Open Access 4: 1-8.

203. Alireza Heidari (2017) Different high-resolution simulations of medical, medicinal, clinical, pharmaceutical and therapeutics oncology of human breast cancer translational nano drugs delivery treatment process under synchrotron and x-ray radiations. J Oral Cancer Res 1: 12-17.

204. Alireza Heidari (2017) Vibrational decihertz (dHz), centihertz $(\mathrm{cHz})$, millihertz $(\mathrm{mHz})$, microhertz $(\mu \mathrm{Hz})$, nanohertz $(\mathrm{nHz})$, picohertz $(\mathrm{pHz})$, femtohertz $(\mathrm{fHz})$, attohertz $(\mathrm{aHz})$, zeptohertz $(\mathrm{zHz})$ and yoctohertz $(\mathrm{yHz})$ imaging and spectroscopy comparative study on malignant and benign human cancer cells and tissues under synchrotron radiation. International Journal of Biomedicine 7: 335-340.

205. Alireza Heidari (2017) Force spectroscopy and fluorescence spectroscopy comparative study on malignant and benign human cancer cells and tissues with the passage of time under synchrotron radiation. EC Cancer 2: 239-246.

206. Alireza Heidari (2017) Photoacoustic spectroscopy, photoemission spectroscopy and photothermal spectroscopy comparative study on malignant and benign human cancer cells and tissues with the passage of time under synchrotron radiation. BAOJ Cancer Res Ther 3: 045-052.

207. Alireza Heidari (2017) J-spectroscopy, exchange spectroscopy (EXSY), nuclear overhauser effect spectroscopy (NOESY) and total correlation spectroscopy (TOCSY) comparative study on malignant and benign human cancer cells and tissues under synchrotron radiation. EMS Eng Sci J 1: 006-013.

208. Alireza Heidari (2017) Neutron spin echo spectroscopy and spin noise spectroscopy comparative study on malignant and benign human cancer cells and tissues with the passage of time under synchrotron radiation. Int J Biopharm Sci 1: 103-107.

209. Alireza Heidari (2017) Vibrational decahertz (daHz), hectohertz $(\mathrm{hHz})$, kilohertz $(\mathrm{KHz})$, megahertz $(\mathrm{MHz})$, gigahertz $(\mathrm{GHz})$, terahertz $(\mathrm{THz})$, petahertz $(\mathrm{PHz})$, exahertz $(\mathrm{EHz})$, zettahertz $(\mathrm{ZHz})$ and yottahertz $(\mathrm{YHz})$ imaging and spectroscopy comparative study on malignant and benign human cancer cells and tissues under synchrotron radiation. Madridge J Anal Sci Instrum 2: 41-46.

210. Alireza Heidari (2018) Two-dimensional infrared correlation spectroscopy, linear two-dimensional infrared spectroscopy and non-linear two-dimensional infrared spectroscopy comparative study on malignant and benign human cancer cells and tissues under synchrotron radiation with the passage of time. J Mater Sci Nanotechnol 6: 101.

211. Alireza Heidari (2018) Fourier transform infrared (FTIR) spectroscopy, near-infrared spectroscopy (NIRS) and mid-infrared spectroscopy (MIRS) comparative study on malignant and benign human cancer cells and tissues under synchrotron radiation with the passage of time. Int $J$ Nanotechnol Nanomed 3: 1-6.

212. Alireza Heidari (2018) Infrared photo dissociation spectroscopy and infrared correlation table spectroscopy com- 
parative study on malignant and benign human cancer cells and tissues under synchrotron radiation with the passage of time. Austin Pharmacol Pharm 3: 1011.

213. Alireza Heidari (2017) Novel and transcendental prevention, diagnosis and treatment strategies for investigation of interaction among human blood cancer cells, tissues, tumors and metastases with synchrotron radiation under anti-cancer nano drugs delivery efficacy using matlab modeling and simulation. Madridge J Nov Drug Res 1: 18-24.

214. Alireza Heidari (2018) Comparative study on malignant and benign human cancer cells and tissues with the passage of time under synchrotron radiation. Open Access $\mathrm{J}$ Trans Med Res 2: 00026-00032.

215. Marcia Regina Risso Gobato, Ricardo Gobato, Alireza Heidari (2018) Planting of jaboticaba trees for landscape repair of degraded area. Landscape Architecture and Regional Planning 3: 1-9.

216. Alireza Heidari (2018) Fluorescence spectroscopy, phosphorescence spectroscopy and luminescence spectroscopy comparative study on malignant and benign human cancer cells and tissues under synchrotron radiation with the passage of time. SM J Clin Med Imaging 4: 1018.

217. Alireza Heidari (2018) Nuclear inelastic scattering spectroscopy (NISS) and nuclear inelastic absorption spectroscopy (NIAS) comparative study on malignant and benign human cancer cells and tissues under synchrotron radiation. Int J Pharm Sci 2: 1-14.

218. Alireza Heidari (2018) X-ray diffraction (XRD), powder $x$-ray diffraction (PXRD) and energy-dispersive $x$-ray diffraction (EDXRD) comparative study on malignant and benign human cancer cells and tissues under synchrotron radiation. J Oncol Res 2: 1-14.

219. Alireza Heidari (2018) Correlation two-dimensional nuclear magnetic resonance (NMR) (2d-NMR) (COSY) imaging and spectroscopy comparative study on malignant and benign human cancer cells and tissues under synchrotron radiation. EMS Can Sci 1: 001.

220. Alireza Heidari (2018) Thermal spectroscopy, photothermal spectroscopy, thermal microspectroscopy, photothermal microspectroscopy, thermal macrospectroscopy and photothermal macrospectroscopy comparative study on malignant and benign human cancer cells and tissues with the passage of time under synchrotron radiation. SM J Biometrics Biostat 3: 1024.

221. Alireza Heidari (2018) A modern and comprehensive experimental biospectroscopic comparative study on human common cancers' cells, tissues and tumors before and after synchrotron radiation therapy. Open Acc J Oncol Med 1.

222. Alireza Heidari (2018) Heteronuclear correlation experiments such as heteronuclear single-quantum correlation spectroscopy (HSQC), heteronuclear multiple-quantum correlation spectroscopy (HMQC) and heteronuclear multiple-bond correlation spectroscopy (HMBC) comparative study on malignant and benign human endocrinology and thyroid cancer cells and tissues under synchrotron radiation. J Endocrinol Thyroid Res 3: 555604.

223. Alireza Heidari (2018) Nuclear resonance vibrational spectroscopy (NRVS), nuclear inelastic scattering spectroscopy (NISS), nuclear inelastic absorption spectroscopy (NIAS) and nuclear resonant inelastic $x$-ray scattering spectroscopy (NRIXSS) comparative study on malignant and benign human cancer cells and tissues under synchrotron radiation. Int J Bioorg Chem Mol Biol 6: 1-5.

224. Alireza Heidari (2018) A novel and modern experimental approach to vibrational circular dichroism spectroscopy and video spectroscopy comparative study on malignant and benign human cancer cells and tissues with the passage of time under white and monochromatic synchrotron radiation. Glob J Endocrinol Metab 1: 000514-000519.

225. Alireza Heidari (2018) Pros and cons controversy on heteronuclear correlation experiments such as heteronuclear single-quantum correlation spectroscopy (HSQC), heteronuclear multiple-quantum correlation spectroscopy (HMQC) and heteronuclear multiple-bond correlation spectroscopy (HMBC) comparative study on malignant and benign human cancer cells and tissues under synchrotron radiation. EMS Pharma J 1: 002.

226. Alireza Heidari (2018) A modern comparative and comprehensive experimental biospectroscopic study on different types of infrared spectroscopy of malignant and benign human cancer cells and tissues with the passage of time under synchrotron radiation. J Analyt Molecul Tech 3: 8.

227. Alireza Heidari (2018) Investigation of cancer types using synchrotron technology for proton beam therapy: An experimental biospectroscopic comparative study. European Modern Studies Journal 2: 13-29.

228. Alireza Heidari (2018) Saturated spectroscopy and unsaturated spectroscopy comparative study on malignant and benign human cancer cells and tissues with the passage of time under synchrotron radiation. Imaging $\mathrm{J}$ Clin Medical Sci 5: 001-007.

229. Alireza Heidari (2018) Small-angle neutron scattering (SANS) and wide-angle x-ray diffraction (WAXD) comparative study on malignant and benign human cancer cells and tissues under synchrotron radiation. Int J Bioorg Chem Mol Biol 6: 1-6.

230. Alireza Heidari (2018) Investigation of bladder cancer, breast cancer, colorectal cancer, endometrial cancer, kidney cancer, leukemia, liver, lung cancer, melanoma, non-hodgkin lymphoma, pancreatic cancer, prostate cancer, thyroid cancer and non-melanoma skin cancer using synchrotron technology for proton beam therapy: An experimental biospectroscopic comparative study. Ther Res Skin Dis 1: 1-9.

231. Alireza Heidari (2018) Attenuated Total Reflectance Fourier Transform Infrared (ATR-FTIR) Spectroscopy, Micro-Attenuated Total Reflectance Fourier Transform Infrared (Micro-ATR-FTIR) Spectroscopy and Macro-Attenuated Total Reflectance Fourier Transform Infrared (Macro-ATR-FTIR) Spectroscopy Comparative Study on Malignant and Benign Human Cancer Cells and Tissues under Synchrotron Radiation with the Passage of Time. International Journal of Chemistry Papers 2: 1-12.

232. Alireza Heidari (2018) Mössbauer spectroscopy, mössbauer emission spectroscopy and ${ }^{57} \mathrm{Fe}$ mössbauer spectroscopy comparative study on malignant and benign human cancer cells and tissues under synchrotron radiation. Acta Scientific Cancer Biology 2: 17-20.

233. Sabine Szunerits, Rabah Boukherroub (2016) Antibacterial activity of graphene-based materials. Journal of Materials Chemistry B 4: 6892-6912.

234. Elahe Dadvar, Roshanak Rezaei Kalantary, Homayon Ahmad Panahi, Majid Peyravi (2016) Efficiency of polymeric membrane graphene oxide-TiO2 for removal of azo dye. Journal of Chemistry 2017: 13.

235. Elahe Dadvar, Roshanak Rezaei Kalantary, Homayon Ahmad Panahi, Majid Peyravi (2017) Removing phenanthrene by polyethersulfone/graphene oxide-titanum dioxide membrane. Mater Express 7: 457-468. 
236. Du Chunhui, Wu Chunjin, Li Jing, Sun Kaixiang (2016) Chitosan functionalized graphene oxide/polyvinylidene fluoride hybrid ultrafiltration membrane and preparation method thereof. Citation Patent CN105903359A, Publication Number: CN 105617882.

237. He L, Cui B, Cai L, Wang X, Gao H, et al. (2016) Modified polyvinylidene fluoride super-hydrophobic material and preparation method thereof. Citation Patent CN102604275A.

238. Xu N, Li W, Xing W (2012) Enhanced graphene oxide hollow fiber composite membrane and preparation method thereof. Citation Patent CN102166484A.

239. Baoxia Mi, Meng Hu (2015) Layer-by-layer assembly of graphene oxide membranes via electrostatic interaction and elucidation of water and solute transport mechanisms. Publication Number: US 20150258506 A1.

240. Peng W, Bo T, Lianbin Z (2015) Method for preparing microstructure arrays on the surface of thin film material. Publication Number: WO 2017021936 A1.

241. Jae MH, Seong RH, Hyun CP, Yong SK, Kyu HA (1996) Method for preparing porous membranes utilizing water or organic vapor adsorption. Publication Number: US5708040 A.

242. Meng CK, Wai KW, Yamuna A, Daniel OH, Mohammed JK, et al. (2015) Graphene oxide/polymer composite membranes and methods of forming thereof. Publication Number: WO2015060782 A1.

243. Ho BP, Hyo WK, Hee WY, Byung MY (2016) Composite separation membrane including graphene oxide coating layer and method for manufacturing the same. Publication Number: US20160074814 A1.

244. Bano S, Mahmood A, Seong JK, Lee KH (2016) Nanocomposite ultrafiltration membrane containing graphene oxide or reduced graphene oxide and preparation method thereof. Publication Number: US20160303518A1.

245. Feng K, Tang B, Wu P (2015) Graphene oxide-polymer hybrid proton exchange membrane and preparation meth- od thereof. Publication Number: CN 103012824B.

246. Bong GC, Yun SH, Young CP, Doo Hwan Jung, Won Hi Hong, et al. (2012) Enhanced transport properties in polymer electrolyte composite membranes with graphene oxide sheets. Carbon 50: 5395-5402.

247. Nouran AS, Abdel Hamied B, Amal Mohamed Kamal E, Adham Ramzy R (2014) Polymer-carbon nanotube nanocomposite porous membranes. Publication Number: US 20140209539 A1.

248. Rahul N, Peter B, Andre G (2014) Separation of water using a membrane. Publication Number: WO 2014027197A1.

249. Zhengtang Luo, Alan T Johnson (2014) High yield preparation of macroscopic graphene oxide membranes. US Patent 8821745.

250. Xu T, Wang Y (2014) A high-water flux forward osmosis composite membrane and its preparation method. Publication Number: CN 103977718.

251. Hong WS, Liu WR, Qiu YQ, Yang YQ, Hu Qian J, et al. (2016) Graphene membrane filtration and its production. Publication Number CN 106139929.

252. Miriam R, Rebecca I, Hongfei L, Lee B, Arthur C, et al. (2016) Attachment of graphene and metal or metal oxide-modified graphene to organic polymers used in organic fuel cells. Publication Number: US 20160359183 A1.

253. Rachel MF, Daniel TD, Richard PS, Kevin WH, CR South (2009) Recent progress in graphene-related nanotechnologies. Recent Pat Nanotechno 3: 164-176.

254. Wenchao T, Xiangyang Z, Zhiqiang Ch, Haoyue Ji (2016) A Review of Graphene on NEMS. Recent Pat Nanotechnol 10: 3-10.

255. Rachel MF, Hough WL, Chopra N, Hathcock KW (2012) Advances in graphene related technologies: Synthesis, devices and outlook. Recent Pat Nanotechnol 6: 79-98.

256. Joonwon B, Chang SL, Oh Seok K (2016) Energy efficient graphene based high performance capacitors. Recent Pat Nanotechnol 11: 93-100. 